\title{
Synthesis, anti-inflammatory,
} using click chemistry

Kishore Kumar Angajala', Sunitha Vianala', Ramesh Macha' ${ }^{1}$, M. Raghavender ${ }^{1}$, Murali Krishna Thupurani ${ }^{2}$ and P. J. Pathi ${ }^{*}$

\begin{abstract}
Background: Nonsteroidal anti-inflammatory drugs are of vast therapeutic benefit in the treatment of different types of inflammatory conditions. 1,2,3-Triazoles and their derivatives have a wide range of applications as anti-bacterial, anti-fungal, anti-tubercular, cytostatic, anti-HIV, anti-allergic, anti-neoplastic and anti-inflammatory (AI) agents. Considering the individual biological and medicinal importance of ibuprofen and 1,2,3-triazoles, we wanted to explore novel chemical entities based on ibuprofen and triazole moieties towards their biological significance.

Results: Click chemistry has utilized as an ideal strategy to prepare novel ibuprofen-based 1,4-disubstituted 1,2,3-triazole containing molecules. These compounds were screened for their in vivo Al activity, among all the synthesized analogues $\mathbf{1 3 0}$ was shown potent effect than the reference Al drug ibuprofen at the same concentration (10 mg/ $\mathrm{kg}$ body weight). Compounds $\mathbf{1 3 \mathbf { l }}, \mathbf{1 3 \mathbf { g }}, \mathbf{1 3 c}, \mathbf{1 3 k}, \mathbf{1 3 \mathbf { i }}, \mathbf{1 3 n}, \mathbf{1 3 m}$ and $\mathbf{1 3 \mathbf { j }}$ were shown significant Al activity. These triazole analogues were also screened for their bactericidal profile. Compounds $\mathbf{1 3 c}, \mathbf{1 3 i}, \mathbf{1 3 I}$ and $\mathbf{1 3 0}$ exhibited considerable bactericidal activity against gram positive and gram negative strains. In addition to this, molecular docking studies were also carried out into cyclooxygenase-2 active site to predict the affinity and orientation of these novel compounds (13a-q).

Conclusions: In summary, we have designed and synthesized 1,2,3-triazole analogues of ibuprofen in good yields using Click chemistry approach. Al and bactericidal activities of these compounds were evaluated and shown remarkable results.
\end{abstract}

Keywords: Click chemistry, Triazoles, Ibuprofen, Anti-inflammatory, Docking, Bactericidal

\section{Background}

The nonsteroidal anti-inflammatory drugs are extensively applied for the treatment of analgesic, antipyretic, rheumatic arthritis and in high doses these are used to treat inflammatory diseases. Prolonged oral administration of these drugs was reported for frequent adverse effects on the gastrointestinal tract (GIT) (Allison et al. 1992; Lazzaroni and Bianchi Porro 2004) and subsequently leads

\footnotetext{
*Correspondence: pjp.ou.chem@gmail.com

1 Department of Chemistry, University College of Science, Saifabad,

Osmania University, Hyderabad, Telangana 500004, India

Full list of author information is available at the end of the article
}

to obstacles such as kidney damage (Ruiz and Lowenthal 1997), gastric ulcer (Alsarra et al. 2010) and hepatotoxicity (Tan et al. 2007). This is most likely due to the presence of free carboxyl group on Nonsteroidal antiinflammatory drugs (NSAIDs) (Mishra et al. 2008). The GIT mucosal injury problems produced by NSAIDs are commonly believed to be caused by two different mechanisms. One is local irritation produced by free carboxylic acid group and inhibition of prostaglandin biosynthesis in the GIT. The second has indirect effect can be attributed to combination of an ion trapping mechanism of NSAIDs from the lumen into the mucosa. Thus, free

\section{Springer Open}


acidic group plays a key role in keeping the effectiveness and producing the gastric ulceration as well. Hence, there remains a compelling need for effective NSAIDs with an improved safety profile and strategy for suppressing inflammation with least side effects.

It has been reported (Kalgutkar et al. 2000a, b, 2002; Shanbhag et al. 1992; Tozkoparan et al. 2000) that conversion of the carboxyl group containing NSAIDs to ester, amide functions and some other modifications retains the anti-inflammatory activity of the parent NSAIDs and makes them more selective towards cyclooxygenase-2 (COX-2) enzyme. These modifications were inspired us to concentrate on the carboxyl side chain of ibuprofen to design novel class of molecules. During the synthesis of these analogues, we planned to utilize Click chemistry as key reaction. Click reaction is one of the most popular reactions for the construction of triazoles. Concept of this reaction discovered by the groups of Sharpless (Rostovtsev et al. 2002) and Meldal (Tornøe et al. 2002) independently. It is a copper(I)-catalyzed 1,3-dipolar cycloaddition (CuAAC) reaction which involves alkyne and azide as key partners to deliver 1,2,3-triazoles. Click chemistry has recently emerged to become a powerful tool in drug discovery. The 1,4-disubstituted 1,2,3-triazoles obtained from CuAAC reactions are found to possess wide applications in several research fields including synthetic organic (Liu et al. 2008; Wacharasindhu et al. 2009), biological (Romeo et al. 2015) and medicinal chemistry (Liang et al. 2015). 1,2,3-Triazole is one of the key structural unit found in a wide variety of bioactive molecules tazobactam (Yang et al. 1999), cefatrizine (Dunn et al. 1976), carboxyamidotriazole (Guo et al. 2008).

In this paper, we framed out our studies to synthesize analogues of ibuprofen, a widely used drug among other clinically existing NSAIDs. Free carboxyl group in ibuprofen could be modified to obtain more potent analogues. Derivatives of ibuprofen with modified carboxylic acid functionality were shown in Fig. 1 (1-3) (Bansal et al. 2015; Yadav et al. 2006). In compound 1, carboxyl group modified as an aromatic motif. Whereas in compounds 2-3, acid functionality diminished by making different substituted aromatic amides. Interestingly, we found that some molecules having 1,2,3-triazoles (4-6, Fig. 1) (Rao et al. 2014; Haftchenary et al. 2015; Shafi et al. 2012) also showed good anti-inflammatory properties. Considering the individual biological activities, medicinal importance of ibuprofen and 1,4-disubstituted 1,2,3-triazoles, we designed novel class of small molecules (7, Fig. 2) having these two pharmacophores in single frame work through an aromatic linker. Resorcinol could be a useful moiety to link ibuprofen and 1,2,3-triazoles via $\mathrm{C}-\mathrm{C}$ and $\mathrm{C}-\mathrm{O}$ bonds respectively. The more active position (4th) of resorcinol was linked to carboxyl group of ibuprofen via $\mathrm{C}-\mathrm{C}$ bond to obtain a novel compound which having ibuprofen as a major structural backbone and key resorcinol moiety. We utilized more reactive hydroxyl functionality, which is present at para position of the linker to make the<smiles>CC(=O)Oc1ccc(NC(=O)C(C)c2ccc(CC(C)C)cc2)cc1</smiles><smiles>[O-]/[N+](=C\c1cn(-c2ccccc2)nn1)c1ccccc1</smiles>

4<smiles>[R]n1cc(COC(=O)/C=C/C=C/c2ccc3c(c2)OCO3)nn1</smiles>

Fig. 1 Examples of COX-2 inhibitors/anti-inflammatory molecules containing ibuprofen and triazole moieties 


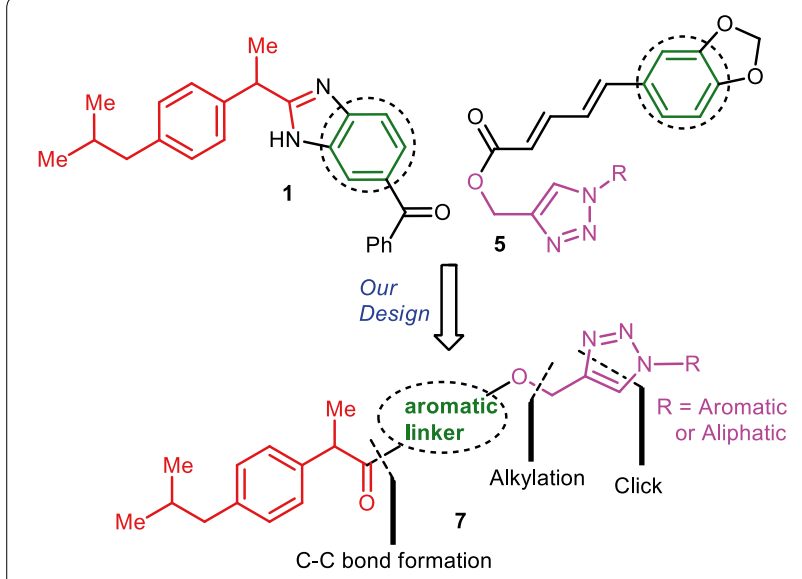

Fig. 2 Design of novel molecules $\mathbf{7}$ from $\mathbf{1}$ and $\mathbf{5}$ containing ibuprofen-aromatic linker-triazole moieties and their key disconnections

propargyl handle. Using Click chemistry approach, this was further diversified by treating with different azides to give novel analogues that contain ibuprofen, resorcinol and 1,4-disubstituted 1,2,3-triazoles as substructures.

In recent years, the multidrug resistance of microbial pathogens has heightened the urgency to develop new antibacterial agents. Having the advantages of mono therapy of an anti-inflammatory drug with anti-microbial properties, here we studied bactericidal activity along with anti-inflammatory activity of the newly synthesized triazoles.

\section{Results and discussion Chemistry}

As shown in Scheme 1, 1-(2,4-dihydroxyphenyl)-2-(4isobutylphenyl)propan-1-one (10) was prepared by heating of resorcinol (9) and ibuprofen (8) in the presence of freshly fused $\mathrm{ZnCl}_{2}$. For $\mathrm{O}$-alkylation, compound 10 was refluxed with propargyl bromide and potassium carbonate in dry acetone for $8 \mathrm{~h}$. In this reaction we got para propargylated compound (11) as major product with $85 \%$ yield. The reason for formation of para propargylated product as major may be explained on the basis of mesomeric effect and steric factors; ortho hydroxy group will have less nucleophilicity than para hydroxyl group. Major product (11) was separated and analyzed by ${ }^{1} \mathrm{H}$ NMR spectroscopy, which showed characteristic singlet at $\delta 12.91$ due to presence of chelated phenolic hydrogen of ortho hydroxyl group and singlet for two protons at $\delta$ $4.66\left(\mathrm{O}-\mathrm{CH}_{2}-\right)$, triplet for one proton at $\delta 2.53(\equiv \mathrm{CH})$ indicates the formations of $\mathrm{O}$-propargylation. With this evidence it is confirmed that the resulting major product was 1-(2-hydroxy-4-(prop-2-yn-1-yloxy)phenyl)-2-(4isobutylphenyl)propan-1-one (11).

Then we synthesized various aliphatic and aromatic azides (12a-q, Fig. 3) by utilizing literature protocols (Lee et al. 2012; Kumar et al. 2014). To prepare alkyl azides, corresponding alkyl halide was heated at $80-90{ }^{\circ} \mathrm{C}$ with $\mathrm{NaN}_{3}$ in DMF. Aromatic azides were prepared from different substituted anilines using diazotization followed by treatment with $\mathrm{NaN}_{3}$.<smiles>CC(C)Cc1ccc(C(C)C(=O)O)cc1</smiles><smiles>[R]Cn1cc(COc2ccc(C(=O)C(C)c3ccc(CC(C)C)cc3)c(O)c2)nn1</smiles>
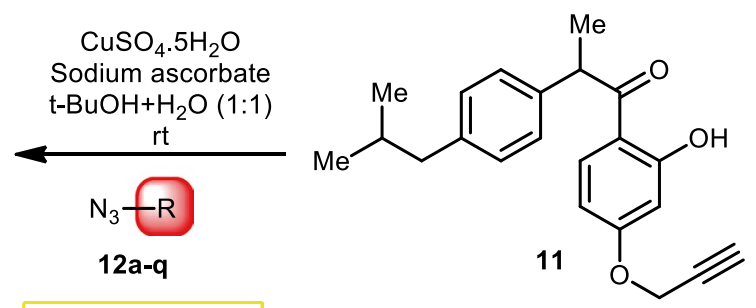

"Click chemistry" 
1,3-diploar cycloaddition between 1-(2-hydroxy-4(prop-2-yn-1-yloxy)phenyl)-2-(4-isobutylphenyl)-propan-1-one (11) and various aromatic, aliphatic azides $(12 \mathbf{a}-\mathbf{q})$ produced seventeen novel 1,4-disubstituted 1,2,3-triazoles in good to excellent yields (13a-q, Fig. 4). All the synthesized compounds were thoroughly analyzed by ${ }^{1} \mathrm{H}-\mathrm{NMR},{ }^{13} \mathrm{C}-\mathrm{NMR}$ and LRMS analytical techniques. Purity was determined by HPLC using the condition specified in each case: column, mobile phase, flow rate (Additional file 1).

\section{Biological study}

\section{In vivo anti-inflammatory activity}

The in vivo anti-inflammatory activity of the synthesized novel triazole moiety containing molecules $(\mathbf{1 3 a}-\mathbf{q})$ was determined at the dose of $10 \mathrm{mg} / \mathrm{kg}$ body weight using carrageenan-induced rat paw edema model (Winter et al. 1962). Anti-inflammatory activity was calculated at hourly intervals up to $6 \mathrm{~h}$ after injection and results were summarized in Table 1 as the mean \pm SEM paw volume $(\mathrm{mL})$ and the percentage anti-inflammatory activity. The paw volume differences were compared between the treated animals and the control group. Percentage inhibition was calculated as per the formula, \% inhibition $=\left[\left(\mathrm{V}_{\mathrm{o}}-\mathrm{V}_{\mathrm{t}}\right) / \mathrm{V}_{\mathrm{o}}\right] \times 100$, where $\mathrm{V}_{\mathrm{o}}=$ volume of the paw control at time $t, V_{t}=$ volume of the paw of drug treated at time $t$. The maximum anti-inflammatory activity was obtained after $3 \mathrm{~h}$ which is the time required for reaching the maximum activity, soon after gradually decreased for the next $2 \mathrm{~h}$.

Compounds $13 \mathbf{a}-\mathbf{q}$, showed mild to excellent antiinflammatory activities (47.00-94.01\% at $3 \mathrm{~h}, 55.47-$ $96.35 \%$ at $4 \mathrm{~h}$ and $56.87-95.62 \%$ at $5 \mathrm{~h}$ ). It is interesting

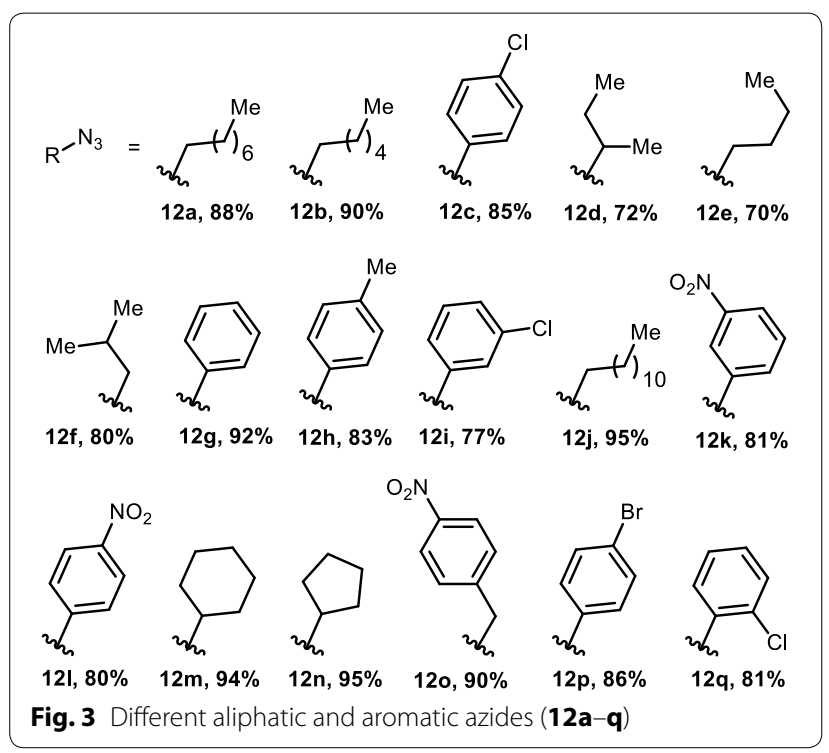

to note that presence of electron withdrawing group or atom $\left(\mathrm{NO}_{2}\right.$ or $\left.\mathrm{Cl}\right)$ at meta or para $\left(\mathrm{C}_{3}\right.$ or $\left.\mathrm{C}_{4}\right)$ positions of benzyl or phenyl ring on triazole leads to significant increase in the activity. Among these triazoles (13a-q), compound 130 bearing a 4-nitrobenzyl group on the triazole moiety exhibited most potent activity $94.01 \%$ at $3 \mathrm{~h}, 96.35 \%$ at $4 \mathrm{~h}, 95.62 \%$ at $5 \mathrm{~h}$ and $94.17 \%$ at $6 \mathrm{~h}$ with compare to reference drug (93.16\% at $3 \mathrm{~h}, 95.62 \%$ at $4 \mathrm{~h}$, $95.62 \%$ at $5 \mathrm{~h}$ and $94.70 \%$ at $6 \mathrm{~h}$ ). Compound 131 bearing a 4-nitrophenyl group on the triazole moiety showed good anti-inflammatory activity of $90.59 \%$ at $3 \mathrm{~h}, 93.43 \%$ at $4 \mathrm{~h}$ and $93.12 \%$ at $5 \mathrm{~h}$. The 1,4-disubstituted 1,2,3-triazole nucleus bearing phenyl (13g), 4-chloro phenyl (13c) were shown considerable inhibition of edema 91.24 and $87.59 \%$ respectively at $4 \mathrm{~h}$. Moderate activity was observed with respect to compounds 13k (86.13\%), 13i $(85.40 \%), \mathbf{1 3 n}(84.67 \%)$ and $\mathbf{1 3 m}(81.02 \%)$ at $4 \mathrm{~h}$.

\section{Bactericidal activity}

According to the results obtained, all the bacterial strains noticed high susceptible nature towards the compounds tested. Among the tested triazoles, compounds 13c, 13i, 131 and 130 exhibited high bactericidal activity. The minimum inhibitory concentration (MIC) of 130 against tested bacterial strains is comparable with that from standard antibiotic drug cefixime (Table 2). On the other hand, compounds 13l, 13c and 13i also produced significant MIC and minimum bactericidal concentration (MBC) values against tested human pathogenic organisms. These results indicates that electron withdrawing group or atom $\left(\mathrm{NO}_{2}\right.$ or $\left.\mathrm{Cl}\right)$ at meta or para positions of benzyl or phenyl ring attached to triazole may increasing the bactericidal activity than aliphatic and electron donating aryl substituted triazoles. By the present investigation, it has been understood that the synthesized compounds are highly active against gram positive strain compared to gram negative strains. Among the screened bacterial strains methicillin-resistant Staphylococcus aureus (MRSA) was found most susceptible MIC (12.5) and MBC (15.1) values for compound 130 which were almost nearer to the values $<13.5$ and $<13$ of positive control.

\section{Molecular modeling approach}

The successful docking has been performed for all newly synthesized target compounds (13a-q) using genetic optimization for ligand docking (GOLD) algorithm version 2.0 (Verdonk et al. 2003). The GOLD program uses a genetic algorithm (GA) to explore the full range of the rotational flexibility of selected receptor hydrogens and ligand flexibility. The 3D crystallographic structure of COX-2 (PDB code 4PH9) (Orlando et al. 2015) was used as template selected from RCSB protein data bank (PDB) 
<smiles>[R]c1cn(CCCC)nn1</smiles><smiles>[R]c1cn(-c2cccc(Cl)c2)nn1</smiles><smiles>[R]c1cn(-c2cccc([N+](=O)[O-])c2)nn1</smiles><smiles>[R]c1cn(-c2ccc([N+](=O)[O-])cc2)nn1</smiles><smiles>[R3]c1cn(C2CCCCC2)nn1</smiles><smiles>[R16]c1cn(C2CCCC2)nn1</smiles><smiles>[R16]c1cn(Cc2ccc([N+](=O)[O-])cc2)nn1</smiles><smiles>[R]c1cn(-c2ccc(Br)cc2)nn1</smiles>

$13 p, 86 \%$<smiles>[R]c1cn(-c2ccccc2Cl)nn1</smiles>

13q, $83 \%$<smiles>CCOc1ccc(C(=O)C(C)c2ccc(CC(C)C)cc2)c(O)c1</smiles>

Fig. 4 Derivatives of target compound (13a-q)

for anti-inflammatory activity. The interactions between ligand $(\mathbf{1 3 a}-\mathbf{q})$ and receptor in the modeled complexes were investigated and observed the fitness function ability of COX-2 by all newly synthesized inhibitors. The observed Chem score and Gold fitness scores have been produced in Tables 3 and 4. Binding energies shown in Table 5 were calculated with ArgusLab (Thompson 2004) docking software. Discovery studio visualizer has been utilized to visualize the binding conformations of these analogues in the active site of 4PH9 protein and good binding orientation poses were shown in Figs. 5, 6 and 7.

Among several residues of the active site region of COX-2, TYR356 and ARG121 allows an important role of formation of hydrogen bonds, which favors interaction with COX-2 inhibitor. Molecular binding pattern of ibuprofen with COX-2 revealed that it has hydrogen bonds with ARG121 (bonding distances of 3.01, $2.97 \AA$ ) and TYR356 (bonding distances of 2.42, 5.21 $\AA$ ) shown 
Table 1 In vivo anti-inflammatory activity of novel 1,2,3-triazoles (13a-q)

\begin{tabular}{|c|c|c|c|c|c|c|c|c|}
\hline \multirow[t]{2}{*}{ Compound } & \multicolumn{2}{|l|}{$3 \mathrm{~h}$} & \multicolumn{2}{|l|}{$4 \mathrm{~h}$} & \multicolumn{2}{|l|}{$5 \mathrm{~h}$} & \multicolumn{2}{|l|}{$6 \mathrm{~h}$} \\
\hline & Swelling & Inhibition (\%) & Swelling & Inhibition (\%) & Swelling & Inhibition (\%) & Swelling & Inhibition (\%) \\
\hline \multicolumn{9}{|c|}{ Volume of edema ${ }^{c}(\mathrm{~mL})$ and $\% \mathrm{Al}^{d}$} \\
\hline Control (-) & $1.17 \pm 0.032$ & & $1.37 \pm 0.012$ & & $1.60 \pm 0.019$ & & $1.89 \pm 0.009$ & \\
\hline Ibuprofen & $0.08 \pm 0.021$ & 93.16 & $0.06 \pm 0.027$ & 95.62 & $0.07 \pm 0.027$ & 95.62 & $0.10 \pm 0.021$ & 94.70 \\
\hline $13 a$ & $0.60 \pm 0.015$ & 48.17 & $0.60 \pm 0.004$ & 56.20 & $0.66 \pm 0.004$ & 58.75 & $0.71 \pm 0.012$ & 62.43 \\
\hline 13b & $0.62 \pm 0.024^{a}$ & 47.00 & $0.61 \pm 0.008^{\mathrm{a}}$ & 55.47 & $0.69 \pm 0.008^{a}$ & 56.87 & $0.74 \pm 0.016^{\mathrm{a}}$ & 60.84 \\
\hline $13 c$ & $0.17 \pm 0.020$ & 85.47 & $0.17 \pm 0.016$ & 87.59 & $0.21 \pm 0.009$ & 86.87 & $0.26 \pm 0.011$ & 86.24 \\
\hline 13d & $0.50 \pm 0.007$ & 57.26 & $0.49 \pm 0.019$ & 64.23 & $0.54 \pm 0.009$ & 66.25 & $0.56 \pm 0.015$ & 70.37 \\
\hline $13 e$ & $0.43 \pm 0.011$ & 63.24 & $0.42 \pm 0.023$ & 69.34 & $0.53 \pm 0.013$ & 66.87 & $0.62 \pm 0.018$ & 67.19 \\
\hline $13 f$ & $0.54 \pm 0.015$ & 53.84 & $0.54 \pm 0.010$ & 60.58 & $0.57 \pm 0.019$ & 64.37 & $0.62 \pm 0.011$ & 67.19 \\
\hline $13 g$ & $0.15 \pm 0.017^{a}$ & 87.17 & $0.12 \pm 0.007^{\mathrm{a}}$ & 91.24 & $0.15 \pm 0.014^{\mathrm{a}}$ & 90.62 & $0.20 \pm 0.012^{a}$ & 89.41 \\
\hline $13 \mathrm{~h}$ & $0.40 \pm 0.022$ & 65.81 & $0.49 \pm 0.012$ & 64.23 & $0.56 \pm 0.017$ & 65.00 & $0.60 \pm 0.011$ & 68.25 \\
\hline $13 i$ & $0.23 \pm 0.009^{b}$ & 80.34 & $0.20 \pm 0.019^{b}$ & 85.40 & $0.26 \pm 0.010^{b}$ & 83.75 & $0.31 \pm 0.016^{b}$ & 83.59 \\
\hline $13 j$ & $0.32 \pm 0.012^{b}$ & 72.64 & $0.34 \pm 0.023^{b}$ & 75.18 & $0.40 \pm 0.013^{b}$ & 75.00 & $0.49 \pm 0.011^{b}$ & 74.07 \\
\hline $13 k$ & $0.20 \pm 0.010^{b}$ & 82.90 & $0.19 \pm 0.016^{b}$ & 86.13 & $0.25 \pm 0.012^{b}$ & 84.37 & $0.30 \pm 0.020^{b}$ & 84.20 \\
\hline 131 & $0.11 \pm 0.019^{a}$ & 90.59 & $0.09 \pm 0.011^{\mathrm{a}}$ & 93.43 & $0.11 \pm 0.021^{a}$ & 93.12 & $0.16 \pm 0.012^{a}$ & 91.53 \\
\hline $13 m$ & $0.27 \pm 0.024^{b}$ & 76.92 & $0.26 \pm 0.020^{b}$ & 81.02 & $0.32 \pm 0.011^{b}$ & 80.00 & $0.42 \pm 0.017^{b}$ & 77.77 \\
\hline $13 n$ & $0.25 \pm 0.006^{b}$ & 78.63 & $0.21 \pm 0.012^{b}$ & 84.67 & $0.27 \pm 0.021^{b}$ & 83.12 & $0.35 \pm 0.009^{b}$ & 81.48 \\
\hline 130 & $0.07 \pm 0.011^{\mathrm{a}}$ & 94.01 & $0.05 \pm 0.021^{\mathrm{a}}$ & 96.35 & $0.07 \pm 0.011^{\mathrm{a}}$ & 95.62 & $0.11 \pm 0.014^{\mathrm{a}}$ & 94.17 \\
\hline $13 p$ & $0.36 \pm 0.010$ & 69.23 & $0.40 \pm 0.015$ & 70.80 & $0.47 \pm 0.010$ & 70.62 & $0.52 \pm 0.012$ & 72.48 \\
\hline $13 q$ & $0.38 \pm 0.019$ & 67.52 & $0.45 \pm 0.019$ & 67.15 & $0.26 \pm 0.049^{b}$ & 67.50 & $0.58 \pm 0.020$ & 69.31 \\
\hline
\end{tabular}

a $\mathrm{P}<0.001$ and ${ }^{\mathrm{b}} \mathrm{P}<0.01$. Control $(-)(0.1 \mathrm{~mL}$ of saline solution)

c Values are expressed as mean \pm SEM from six observations and data is analyzed by one way ANOVA followed by Dunnett's ' $t$ ' test

d Values in parentheses [percentage anti-inflammatory activity $(\% \mathrm{Al})$ ]

in Fig. 5. Similarly 130 also formed hydrogen bonds with bond distances viz. 2.91, $2.95 \AA$ for ARG121 and $4.10 \AA$ for TYR356 shown in Fig. 6. It is also forming hydrogen bonds with VAL89, LEU360, LEU93, VAL117, VAL350, LEU353, LEU385, MET523, TYR386, TRP388, PHE519, ILE113, VAL524, ALA528 and GLY527. These interactions of 130 in the COX-2 active site may be driving to have more activity. Compound $\mathbf{1 3 0}$ has the highest fitness score 70.31 and good Chem score 35.66 with binding energy -15.4749 compared with the fitness score 41.19, Chem score 21.39 and binding energy -13.3519 of the standard drug ibuprofen (Tables 3, 4, 5). Compound 131 established hydrogen bonds viz; 2.69, 4.53, $5.42 \AA$ for ARG121 and 3.87, 4.27 $\AA$ for TYR356. It is also formed hydrogen bonds with LEU93, PHE358, VAL89, ILE113, TRP100, PHE358, VAL117, MET114 and TYR116 (Fig. 7). Compound $\mathbf{1 3 1}$ showed fitness score 54.78 and Chem score 38.17 with binding energy -14.1561 .

In this investigation, we discovered that the synthesized triazoles which showed good Chem score and Gold score functions, also exhibited good binding energy values. Finally, molecular docking studies showed good correlation between the in vivo anti-inflammatory activity of final compounds and their binding interactions with COX-2 as well as their Gold fitness scores. Among all compounds, 130 and 131 report good affinities with COX-2 (4PH9).

\section{Experimental section \\ Chemistry \\ Synthesis and characterization data}

Melting points were determined in open capillaries. ${ }^{1} \mathrm{H}$-Nuclear magnetic resonance (NMR) spectra were recorded on Bruker AV 300 and $400 \mathrm{MHz}$ instruments, in $\mathrm{CDCl}_{3}$ using TMS as an internal standard. Chemical shifts are given in $(\delta) \mathrm{ppm}$ and coupling constants $(J)$ are given in Hz. Combinations of the following abbreviations are used to describe NMR spectra: $\mathrm{s}=$ singlet; $\mathrm{d}=$ doublet; $\mathrm{t}=$ triplet; $\mathrm{q}=$ quartet; $\mathrm{m}=$ multiplet. Thin layer chromatography (TLC) was carried out on aluminium sheets coated with silica gel $60 \mathrm{~F}_{254}$ (Merck, 1.05554) and the spots were visualized with UV light at $254 \mathrm{~nm}$ or alternatively by staining with aqueous basic potassium permanganate. Flash column chromatography was performed using silica gel (Merck, 60A, 100-200 mesh). Chromatographic purity by HPLC was determined by using area normalization method and the condition specified in each case: column, mobile phase, flow rate, detection wavelength, and retention times. Commercially 
Table $2 \mathrm{MIC} / \mathrm{MBC}(\mu \mathrm{g} / \mathrm{mL})$ values of synthesized compounds $(13 \mathrm{a}-\mathrm{q})$ and Cefixime against tested bacterial strains

\begin{tabular}{|c|c|c|c|c|c|c|c|c|c|c|c|c|}
\hline \multirow[t]{3}{*}{ Compounds } & \multicolumn{6}{|c|}{ Gram positive } & \multicolumn{6}{|c|}{ Gram negative } \\
\hline & \multicolumn{2}{|l|}{ MRSA } & \multicolumn{2}{|c|}{ B. subtilis } & \multicolumn{2}{|c|}{ B. cereus } & \multicolumn{2}{|l|}{ E. coli } & \multicolumn{2}{|c|}{ K. pneumoniae } & \multicolumn{2}{|c|}{ P. vulgaris } \\
\hline & MIC & MBC & MIC & MBC & MIC & MBC & MIC & MBC & MIC & MBC & MIC & MBC \\
\hline $13 a$ & $>150$ & $>155$ & 109.3 & 112 & 118 & 120 & 98.6 & 100 & $>130$ & $>140$ & $>90$ & $>90$ \\
\hline $13 b$ & 120 & 126 & 88.2 & $>90$ & 102 & 108 & 92.6 & 100 & $>128$ & $>140$ & $>100$ & $>110$ \\
\hline $13 c$ & 24.1 & 27.3 & 28.9 & $>40$ & 32.0 & 42.1 & 28.6 & 30.2 & 38.5 & $>40$ & $>50$ & $>50$ \\
\hline $13 d$ & 30.6 & 31.6 & $>25$ & 30.2 & 45.7 & 50.1 & $>40$ & 42.3 & 62.8 & 65.2 & 78.3 & 80.2 \\
\hline $13 e$ & 57.9 & 60.0 & 60.5 & 70.2 & 79.6 & 82.1 & $>120$ & $>120$ & $>100$ & 105.1 & $>150$ & $>150$ \\
\hline $13 f$ & $>170$ & $>170$ & $>180$ & $>180$ & 88.1 & 90.2 & 112 & 117 & 136 & 138 & 80.3 & 85 \\
\hline $13 g$ & 40.5 & 42.3 & 66.6 & 70.5 & $>60$ & 68.0 & 55.3 & 55.5 & 33.8 & 36.9 & 90.1 & $>100$ \\
\hline $13 \mathrm{~h}$ & $>118$ & $>120$ & $>140$ & $>140$ & 114 & 117 & $>130$ & $<135$ & 175 & 179 & $<200$ & $<200$ \\
\hline $13 i$ & 20.5 & 22.1 & 18.6 & 19.3 & 25.8 & 30.3 & 22.5 & 25.8 & 35.9 & 38.0 & 45.0 & $>50$ \\
\hline $13 j$ & $>188$ & $>190$ & $>153$ & $>160$ & $>160$ & $>160$ & 112 & 113 & $>145$ & $>148$ & $>170$ & $>172$ \\
\hline $13 k$ & 33.6 & $>40$ & 35.9 & 47.0 & 44.6 & 50.2 & $>50$ & 66.0 & 58.2 & 65.0 & $>80$ & $>86$ \\
\hline 131 & 18.5 & 24.9 & 20.5 & 22.8 & 20.7 & 21.0 & 18.2 & 24.1 & 33.6 & 35.1 & 30.9 & 33.5 \\
\hline $13 m$ & $>189$ & $>200$ & $>168$ & $>170$ & 159 & 163 & 149 & 156 & 177 & 180 & 161 & 164 \\
\hline $13 n$ & 36.3 & 39.5 & 58.0 & $>80$ & $>60$ & $>75$ & $>50$ & 58.6 & 80.2 & 92.0 & $>70$ & $>85$ \\
\hline 130 & 12.5 & 15.1 & 12.9 & 13.0 & 12.0 & 12.0 & 15.5 & 20.3 & 25.3 & $>30$ & 28.4 & $>35$ \\
\hline $13 p$ & $>120$ & $>120$ & 98.9 & 102 & $>140$ & $>150$ & 80.6 & 92.8 & $>100$ & $>120$ & $>150$ & $>165$ \\
\hline $13 q$ & $>125$ & $>130$ & $>155$ & 158 & $>160$ & $>160$ & $>110$ & $>115$ & 146 & 148 & 133 & 134 \\
\hline Cefixime & $<13.5$ & $<13$ & 10.2 & 11.0 & 10 & 10 & 13.0 & 13 & 17 & 17.2 & 20.6 & 21.0 \\
\hline
\end{tabular}

MRSA, Methicillin-resistant Staphylococcus aureus, B. subtilis, Bacillus subtilis, B. cereus, Bacillus cereus, E. coli, Escherichia coli, K. pneumoniae, Klebsiella pneumonia, P. Vulgaris, Proteus vulgaris

Table 3 Chem score of novel 1,2,3-triazoles (13a-q)

\begin{tabular}{|c|c|c|c|c|c|c|c|}
\hline Compound & Score & DG & S(hbond) & $\mathrm{S}$ (metal) & S(lipo) & DE(clash) & $\mathrm{DE}$ (int) \\
\hline $13 a$ & 33.75 & -38.96 & 1.77 & 0.00 & 290.03 & 0.79 & 4.43 \\
\hline $13 b$ & 32.60 & -36.75 & 2.67 & 0.00 & 244.12 & 0.75 & 3.40 \\
\hline $13 c$ & 40.43 & -45.28 & 1.94 & 0.00 & 342.10 & 0.75 & 4.10 \\
\hline $13 d$ & 33.17 & -37.99 & 2.69 & 0.00 & 251.40 & 2.10 & 2.72 \\
\hline $13 e$ & 36.23 & -40.09 & 3.56 & 0.00 & 246.17 & 0.11 & 3.75 \\
\hline $13 f$ & 31.89 & -35.41 & 2.70 & 0.00 & 229.21 & 0.09 & 3.43 \\
\hline $13 g$ & 38.65 & -42.06 & 3.58 & 0.00 & 257.62 & 1.20 & 2.20 \\
\hline $13 \mathrm{~h}$ & 36.19 & -40.46 & 3.52 & 0.00 & 246.84 & 2.42 & 1.85 \\
\hline $13 \mathbf{i}$ & 38.03 & -42.37 & 3.58 & 0.00 & 260.74 & 1.87 & 2.47 \\
\hline $13 j$ & 36.76 & -40.21 & 2.34 & 0.00 & 277.60 & 0.28 & 3.18 \\
\hline $13 k$ & 38.84 & -41.32 & 2.98 & 0.00 & 267.56 & 0.08 & 2.40 \\
\hline 131 & 38.17 & -41.17 & 1.94 & 0.00 & 297.19 & 0.47 & 2.52 \\
\hline $13 m$ & 33.96 & -40.00 & 2.91 & 0.00 & 265.74 & 2.71 & 3.32 \\
\hline $13 n$ & 35.60 & -39.63 & 2.61 & 0.00 & 271.34 & 0.05 & 3.99 \\
\hline 130 & 35.66 & -38.89 & 2.39 & 0.00 & 277.42 & 0.46 & 2.76 \\
\hline $13 p$ & 39.07 & -47.49 & 2.12 & 0.00 & 346.07 & 3.77 & 4.65 \\
\hline $13 q$ & 38.39 & -42.34 & 3.52 & 0.00 & 261.98 & 0.56 & 3.39 \\
\hline Ibuprofen & 21.39 & -22.32 & 2.05 & 0.00 & 132.11 & 0.10 & 0.84 \\
\hline
\end{tabular}

Chem score $=\Delta G_{\text {binding }}+P_{\text {clash }}+C_{\text {internal }} P_{\text {internal }}+\left(C_{\text {covalent }} P_{\text {covalent }}+P_{\text {constraint }}\right)$

Score $=-[D G+D E($ clash $)+D E($ int $)]$ 
Table 4 Gold fitness score of novel 1,2,3-triazoles (13a-q)

\begin{tabular}{lcclll}
\hline $\begin{array}{l}\text { Com- } \\
\text { pound }\end{array}$ & Fitness & S(hb_ext) & $\begin{array}{l}\text { S(vdw_ } \\
\text { ext) }\end{array}$ & S(hb_int) & S(vdw_int) \\
\hline 13a & 45.77 & 1.16 & 43.59 & 0.00 & -15.31 \\
13b & 57.40 & 7.50 & 47.91 & 0.00 & -15.97 \\
$\mathbf{1 3 c}$ & 54.17 & 4.29 & 56.67 & 0.00 & -28.04 \\
$\mathbf{1 3 d}$ & 55.57 & 12.48 & 44.01 & 0.00 & -17.43 \\
$\mathbf{1 3 e}$ & 51.45 & 5.51 & 44.29 & 0.00 & -14.96 \\
$\mathbf{1 3 f}$ & 58.76 & 7.97 & 46.45 & 0.00 & -13.09 \\
$\mathbf{1 3 g}$ & 60.01 & 6.00 & 48.17 & 0.00 & -12.22 \\
$\mathbf{1 3 h}$ & 56.08 & 9.08 & 47.70 & 0.00 & -10.33 \\
$\mathbf{1 3 i}$ & 56.08 & 4.69 & 47.22 & 0.00 & -13.53 \\
$\mathbf{1 3 j}$ & 55.11 & 7.17 & 45.42 & 0.00 & -14.52 \\
$\mathbf{1 3 k}$ & 52.03 & 5.07 & 44.07 & 0.00 & -13.63 \\
$\mathbf{1 3 I}$ & 54.78 & 6.10 & 49.52 & 0.00 & -19.42 \\
$\mathbf{1 3 m}$ & 62.06 & 13.54 & 51.06 & 0.00 & -21.69 \\
$\mathbf{1 3 n}$ & 60.05 & 10.71 & 48.89 & 0.00 & -17.88 \\
$\mathbf{1 3 0}$ & 70.31 & 13.07 & 53.66 & 0.00 & -16.55 \\
$\mathbf{1 3 p}$ & 53.70 & 6.05 & 48.38 & 0.00 & -18.86 \\
$\mathbf{1 3 q}$ & 53.01 & 4.73 & 45.93 & 0.00 & -14.87 \\
Ibuprofen & 41.19 & 5.84 & 27.89 & 0.00 & -3.00 \\
\hline
\end{tabular}

Table 5 ArgusLabs binding energy values of novel 1,2,3-triazoles (13a-q)

\begin{tabular}{lllll}
\hline Compound & $\begin{array}{l}\text { Argus B.E. } \\
\text { (K cal/mol) }\end{array}$ & $\begin{array}{l}\text { Elapsed } \\
\text { time (s) }\end{array}$ & $\begin{array}{l}\text { GA dock } \\
\text { energy } \\
\text { (K cal/mol) }\end{array}$ & $\begin{array}{l}\text { Elapsed } \\
\text { time (s) }\end{array}$ \\
\hline $\mathbf{1 3 a}$ & -13.2381 & 22 & -12.0907 & 21 \\
$\mathbf{1 3 b}$ & -12.3289 & 86 & -8.0643 & 21 \\
$\mathbf{1 3 c}$ & -15.5507 & 18 & -11.4343 & 25 \\
$\mathbf{1 3 d}$ & -13.9083 & 19 & -11.899 & 19 \\
$\mathbf{1 3 e}$ & -13.4295 & 26 & -11.7591 & 17 \\
$\mathbf{1 3 f}$ & -13.2227 & 16 & -1.36602 & 16 \\
$\mathbf{1 3 g}$ & -15.0759 & 14 & -13.2652 & 21 \\
$\mathbf{1 3 h}$ & -12.3786 & 16 & -14.1789 & 19 \\
$\mathbf{1 3 i}$ & -15.9765 & 17 & -9.5211 & 19 \\
$\mathbf{1 3 j}$ & -14.9881 & 11 & -15.6249 & 19 \\
$\mathbf{1 3 k}$ & -14.1346 & 14 & -13.3685 & 19 \\
$\mathbf{1 3 |}$ & -14.1561 & 12 & +3.0948 & 17 \\
$\mathbf{1 3 m}$ & -14.1131 & 15 & -12.7818 & 18 \\
$\mathbf{1 3 n}$ & -14.9852 & 14 & -12.7541 & 17 \\
$\mathbf{1 3 0}$ & -15.4749 & 10 & -11.1716 & 20 \\
$\mathbf{1 3 p}$ & -12.1776 & 7 & -12.5944 & 20 \\
$\mathbf{1 3 q}$ & -8.1178 & 7 & -8.7334 & 19 \\
$\mathbf{I b u p r o f e n}$ & -13.3519 & 6 & -4.82611 & 8 \\
\hline & & & & 17 \\
\hline
\end{tabular}

available reagents were used as supplied and some of them were distilled before use. All reactions were performed in oven dried glassware. All solvents were removed by evaporation under reduced pressure.

\section{General procedure for the synthesis}

of 1-(2,4-dihydroxyphenyl)-2-(4-isobutylphenyl) propan-1-one (10)

Ibuprofen (2 g, $9.69 \mathrm{mmol}$ ) was added to fused zinc chloride $(1.98 \mathrm{~g}, 14.54 \mathrm{mmol})$ and heated to $120{ }^{\circ} \mathrm{C}$ for $20 \mathrm{~min}$ then resorcinol (1.06 g, $9.69 \mathrm{mmol})$ was added. The reaction mixture was heated to $140{ }^{\circ} \mathrm{C}$ for $30 \mathrm{~min}$ and monitored by TLC for complete conversion of starting materials. The reaction mixture was allowed to room temperature and was poured into ice cold water $(100 \mathrm{~mL})$, extracted with ethyl acetate $(3 \times 50 \mathrm{~mL})$. The combined organic layers were washed with $5 \% \mathrm{HCl}(50 \mathrm{~mL})$, saturated $\mathrm{NaHCO}_{3}(25 \mathrm{~mL})$ and brine $(2 \times 25 \mathrm{~mL})$. The organic layer was dried over anhydrous sodium sulphate, filtered and concentrated in vacuo. The crude product was purified by column chromatography using 100-200 mesh silica gel, eluted at $10 \%$ ethyl acetate in pet ether to afford 1-(2,4-dihydroxy-phenyl)-2-phenyl-ethanone as light yellow liquid (2.2 g, $75 \%$ ).

Chemical formula: $\mathrm{C}_{19} \mathrm{H}_{22} \mathrm{O}_{3}$; ${ }^{1} \mathrm{H}-\mathrm{NMR}$ (400 $\mathrm{MHz}$, $\left.\mathrm{CDCl}_{3}\right) \delta 12.97(\mathrm{~s}, 1 \mathrm{H}), 7.70(\mathrm{~d}, J=8.82 \mathrm{~Hz}, 1 \mathrm{H}), 7.22-$ $7.16(\mathrm{~m}, 2 \mathrm{H}), 7.12-7.06(\mathrm{~m}, 2 \mathrm{H}), 6.33(\mathrm{~d}, J=2.30 \mathrm{~Hz}$, $1 \mathrm{H}), 6.28(\mathrm{dd}, J=8.78,2.32 \mathrm{~Hz}, 1 \mathrm{H}), 4.60(\mathrm{q}, J=6.79 \mathrm{~Hz}$, $1 \mathrm{H}), 2.44-2.39(\mathrm{~m}, 2 \mathrm{H}), 1.88-1.77(\mathrm{~m}, 1 \mathrm{H}), 1.51(\mathrm{~d}$, $J=6.82 \mathrm{~Hz}, 3 \mathrm{H}), 0.88(\mathrm{~m}, 6 \mathrm{H}) ;{ }^{13} \mathrm{C}-\mathrm{NMR}(100 \mathrm{MHz}$, $\left.\mathrm{CDCl}_{3}\right) \delta 205.3,166.1,163.2,141.3,139.3,133.6,130.5$ (2C), 128.1 (2C), 114.0, 108.9, 104.6, 48.1, 46.6, 31.9, 24.2 (2C), 21.0; LRMS: $(\mathrm{ES}+) m / z=299[\mathrm{M}+1]$.

General procedure for the synthesis of 1-(2-hydroxy-4-(prop2-yn-1-yloxy)phenyl)-2-(4-isobutylphenyl)propan-1-one (11) Compound (10) (2.1 g, $7.038 \mathrm{mmol}$ ) was taken in dry acetone, anhydrous $\mathrm{K}_{2} \mathrm{CO}_{3}(0.972 \mathrm{~g}, 7.038 \mathrm{mmol})$ and propargyl bromide $(0.837 \mathrm{~g}, 7.038, \mathrm{mmol})$ was added. This reaction mixture was refluxed for $8 \mathrm{~h}$. Progress of the reaction was monitored by TLC, the reaction mixture was cooled to room temperature and solvent was removed in vacuo, then diluted with water $(50 \mathrm{~mL})$ and extracted with ethyl acetate $(3 \times 50 \mathrm{~mL})$. The combined organic layers were washed with brine $(2 \times 25 \mathrm{~mL})$. The organic layer was dried over anhydrous sodium sulphate, filtered and concentrated in vacuo. The crude product was purified by column chromatography using 100-200 mesh silica gel, eluted at $5 \%$ ethyl acetate in pet ether to afford 1-(2-hydroxy-4-(prop-2-yn-1-yloxy)phenyl)-2-(4-isobutylphenyl)propan-1-one as light yellow liquid (2 g, $85 \%)$.

Chemical formula: $\mathrm{C}_{22} \mathrm{H}_{24} \mathrm{O}_{3}$; ${ }^{1} \mathrm{H}-\mathrm{NMR}(400 \mathrm{MHz}$, $\left.\mathrm{CDCl}_{3}\right) \delta 12.91(\mathrm{~s}, 1 \mathrm{H}), 7.73(\mathrm{~d}, J=9.04 \mathrm{~Hz}, 1 \mathrm{H})$, 7.20-7.17 (m, 2H), $7.08(\mathrm{~d}, J=8.00 \mathrm{~Hz}, 2 \mathrm{H}), 6.48(\mathrm{~d}$, $J=2.48 \mathrm{~Hz}, 1 \mathrm{H}), 6.40(\mathrm{dd}, J=9.00,2.51 \mathrm{~Hz}, 1 \mathrm{H}), 4.66(\mathrm{~s}$, $2 \mathrm{H}), 4.64-4.57(\mathrm{~m}, 1 \mathrm{H}), 2.53(\mathrm{t}, J=2.32 \mathrm{~Hz}, 1 \mathrm{H}), 2.41(\mathrm{~d}$, $J=7.18 \mathrm{~Hz}, 2 \mathrm{H}), 1.82(\mathrm{~m}, 1 \mathrm{H}), 1.51(\mathrm{~d}, J=6.86 \mathrm{~Hz}, 3 \mathrm{H})$, $0.87(\mathrm{~d}, J=6.60 \mathrm{~Hz}, 6 \mathrm{H}) ;{ }^{13} \mathrm{C}-\mathrm{NMR}\left(75 \mathrm{MHz} \mathrm{CDCl}_{3}\right) \delta$ 


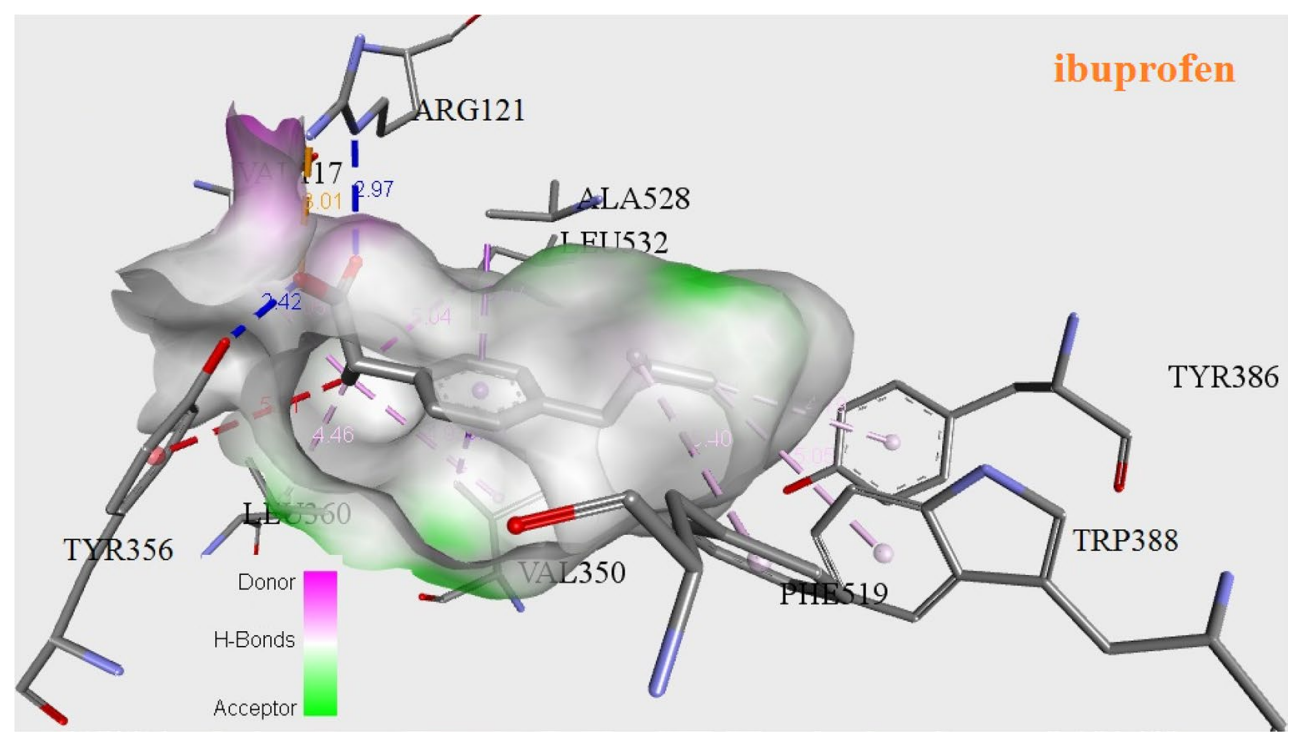

Fig. 5 Docking pose of ibuprofen into the COX-2 (4PH9) active site. Hydrogen bonds are shown in dotted lines

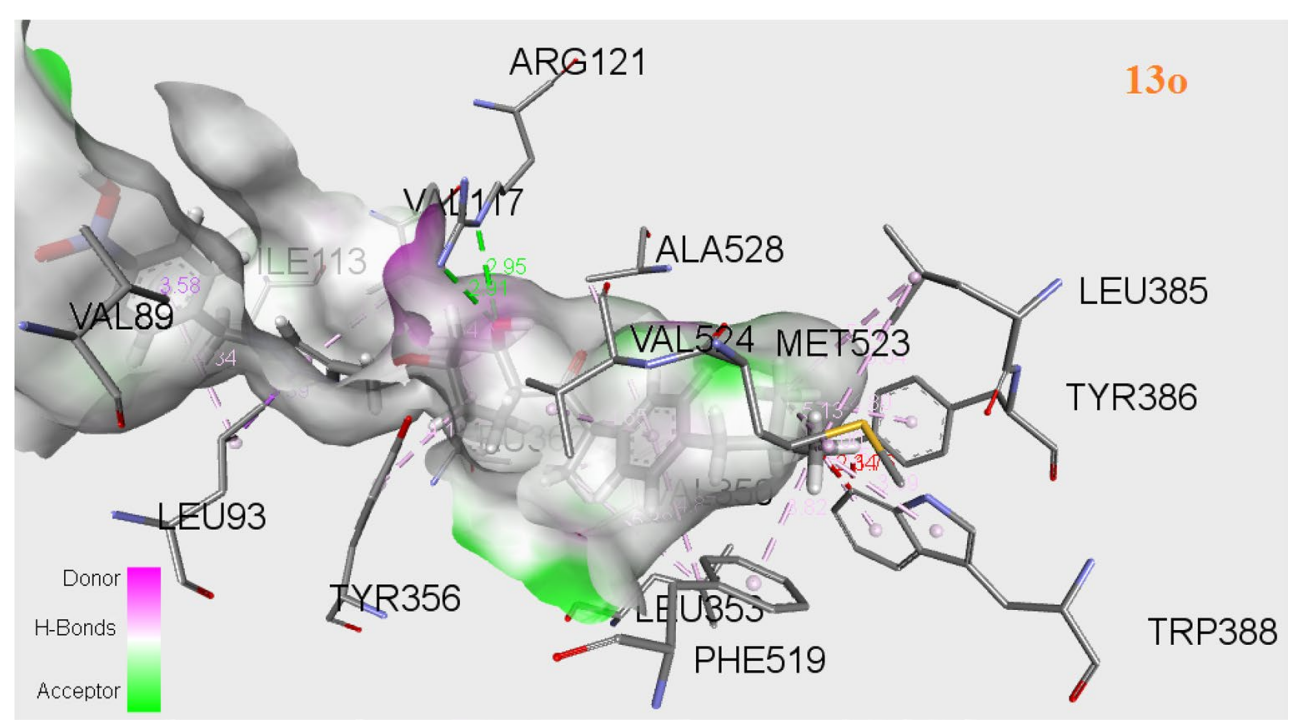

Fig. 6 Docking pose of compound $\mathbf{1 3 0}$ into the $\mathrm{COX}-2$ (4PH9) active site. Hydrogen bonds are shown in dotted lines

206.0, 166.7, 162.7, 141.6, 139.3, 133.6, $130.3(2 \mathrm{C}), 128.7$ (2C), 114.5, 110.1, 105.1, 78.8, 76.8, 57.0, 48.1, 46.9, 31.4, 24.2 (2C), 20.0; LRMS: (ES+) $\mathrm{m} / z=337[\mathrm{M}+1], 359$ $[\mathrm{M}+\mathrm{Na}]$.

\section{General procedure for the synthesis of 1,4-disubstituted 1,2,3-triazole analogues (13a-q)}

Propargyl derivative (11) (100 mg, $0.297 \mathrm{mmol})$ is dissolved in $5 \mathrm{~mL}$ aqueous $t-\mathrm{BuOH}$ (50\%) was added $\mathrm{CuSO}_{4} \cdot 5 \mathrm{H}_{2} \mathrm{O}$ (5 mol\%) followed by sodium ascorbate $(10 \mathrm{~mol} \%)$ and azide $(0.356 \mathrm{mmol})$ was added. The reaction mixture was stirred for $1 \mathrm{~h}$ at room temperature, monitored by TLC. After complete conversion of starting materials the reaction mixture was diluted with water $(25 \mathrm{~mL})$, extracted with ethyl acetate $(3 \times 25 \mathrm{~mL})$. The combined organic layers were washed with brine $(2 \times 25 \mathrm{~mL})$. The organic layer was dried over anhydrous sodium sulphate, filtered and concentrated in vacuo. The crude product was purified by column chromatography using 100-200 mesh silica gel and ethyl acetate in pet ether to afford corresponding 1,4-disubstituted 1,2,3-triazole analogues. 


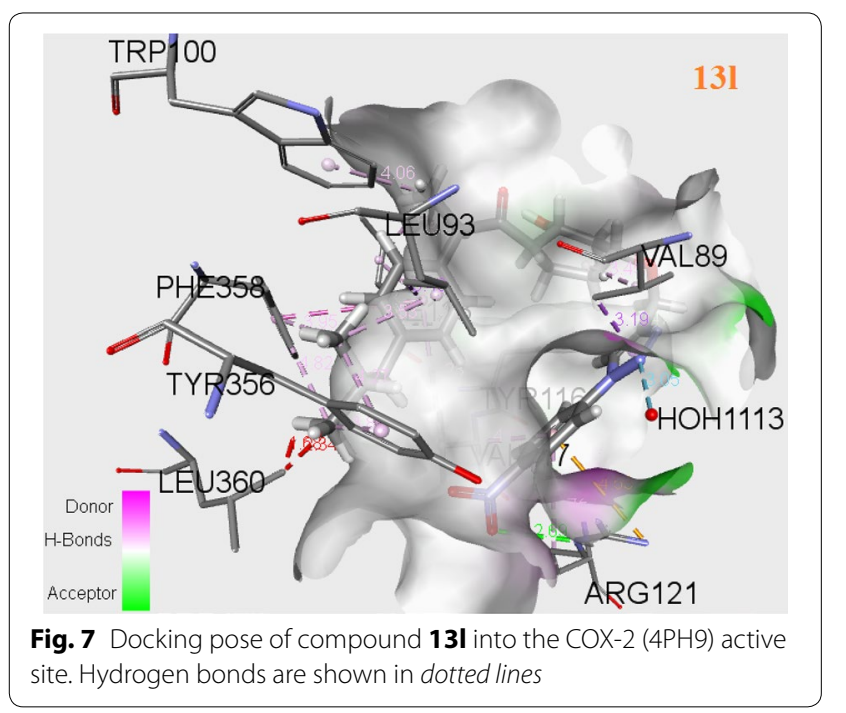

\section{1-(2-Hydroxy-4-((1-octyl-1H-1,2,3-triazol-4-yl)methoxy) phenyl)-2-(4-isobutylphenyl)propan-1-one (13a)}

Chemical formula: $\mathrm{C}_{30} \mathrm{H}_{41} \mathrm{~N}_{3} \mathrm{O}_{3}$; yield: $85 \%$; white solid; mp: 84-86 ${ }^{\circ} \mathrm{C}$; ${ }^{1} \mathrm{H}-\mathrm{NMR}\left(300 \mathrm{MHz}, \mathrm{CDCl}_{3}\right) \delta 12.91$ (s, $1 \mathrm{H}), 7.75(\mathrm{~d}, J=9.03 \mathrm{~Hz}, 1 \mathrm{H}), 7.59(\mathrm{~s}, 1 \mathrm{H}), 7.21(\mathrm{~d}$, $J=8.04 \mathrm{~Hz}, 2 \mathrm{H}), 7.10(\mathrm{~d}, J=8.03 \mathrm{~Hz}, 2 \mathrm{H}), 6.52(\mathrm{~d}$, $J=2.44 \mathrm{~Hz}, 1 \mathrm{H}), 6.46(\mathrm{dd}, J=8.95,2.49 \mathrm{~Hz}, 1 \mathrm{H}), 5.22$ $(\mathrm{s}, 2 \mathrm{H}), 4.64(\mathrm{q}, J=6.85 \mathrm{~Hz}, 1 \mathrm{H}), 4.37(\mathrm{t}, J=7.27 \mathrm{~Hz}$, $2 \mathrm{H}), 2.45(\mathrm{~d}, J=7.15 \mathrm{~Hz}, 2 \mathrm{H}), 1.96-1.81(\mathrm{~m}, 3 \mathrm{H}), 1.55$ $(\mathrm{d}, J=6.84 \mathrm{~Hz}, 3 \mathrm{H}), 1.32-1.27(\mathrm{~m}, 9 \mathrm{H}), 0.94-0.9(\mathrm{~m}$, 10H); ${ }^{13} \mathrm{C}-\mathrm{NMR}\left(75 \mathrm{MHz}, \mathrm{CDCl}_{3}\right) \delta 205.1,166.5,165.0$, $143.9,141.5,139.5,133.2,130.8(2 C), 128.3(2 C), 123.7$, 114.5, 108.9, 103.6, 64.0, 52.5, 48.6, 47.1, 33.9, 32.5, 32.4, 31.3, 31.2, 28.8, 25.0, 24.8 (2C), 21.6, 16.5; LRMS: (ES+) $m / z=492[\mathrm{M}+1], 514[\mathrm{M}+\mathrm{Na}]$; HPLC $98.03 \%$, column: phenomenex luna C8 (2) (250X4.6 mm), mobile phase: $90 \%$ acetonitrile in $0.1 \%$ formic acid, flow rate: $1.0 \mathrm{~mL} / \mathrm{min}$.

\section{1-(4-((1-Hexyl-1H-1,2,3-triazol-4-yl) methoxy)-2-hydroxyphenyl)-2-(4-isobutylphenyl) propan-1-one (13b)}

Chemical formula: $\mathrm{C}_{28} \mathrm{H}_{37} \mathrm{~N}_{3} \mathrm{O}_{3}$; yield: 90 \%; white solid; mp: 83-85 ${ }^{\circ} \mathrm{C}$; ${ }^{1} \mathrm{H}-\mathrm{NMR}$ (300 MHz, $\left.\mathrm{CDCl}_{3}\right) \delta 12.90$ (s, 1H), $7.72(\mathrm{~d}, J=8.97 \mathrm{~Hz}, 1 \mathrm{H}), 7.57(\mathrm{~s}, 1 \mathrm{H}), 7.19(\mathrm{~d}$, $J=7.72 \mathrm{~Hz}, 2 \mathrm{H}), 7.08(\mathrm{~d}, J=7.68 \mathrm{~Hz}, 2 \mathrm{H}), 6.49(\mathrm{~s}, 1 \mathrm{H})$, $6.43(\mathrm{~d}, J=8.87 \mathrm{~Hz}, 1 \mathrm{H}), 5.19(\mathrm{~s}, 2 \mathrm{H}), 4.61(\mathrm{q}, J=6.74 \mathrm{~Hz}$, $1 \mathrm{H}), 4.34(\mathrm{t}, J=7.17 \mathrm{~Hz}, 2 \mathrm{H}), 2.41(\mathrm{~d}, J=7.07 \mathrm{~Hz}, 2 \mathrm{H})$, $1.96-1.76(\mathrm{~m}, 3 \mathrm{H}), 1.51(\mathrm{~d}, J=6.73 \mathrm{~Hz}, 3 \mathrm{H}), 1.26-1.35$ (m, 6H), 0.91-0.84 (m, 9H); ${ }^{13} \mathrm{C}-\mathrm{NMR}\left(75 \mathrm{MHz}, \mathrm{CDCl}_{3}\right) \delta$ 205.2, 166.5, 164.9, 143.9, 141.5, 139.5, 133.3, 130.8 (2C), 128.3 (2C), 123.8, 114.5, 108.9, 103.6, 64.0, 52.5, 48.6, 47.1, 33.4, 32.5, 32.4, 28.5, 24.8 (3C), 21.6, 16.4; LRMS: $(\mathrm{ES}+) \mathrm{m} / z=464[\mathrm{M}+1], 486[\mathrm{M}+\mathrm{Na}] ;$ HPLC $99.12 \%$, column: phenomenex luna C8 (2) (250X4.6 mm), mobile phase: $90 \%$ acetonitrile in $0.1 \%$ formic acid, flow rate: $1.0 \mathrm{~mL} / \mathrm{min}$.

\section{1-(4-((1-(4-Chlorophenyl)-1H-1,2,3-triazol-4-yl) methoxy)-2-hydroxyphenyl)-2-(4-isobutylphenyl) propan-1-one (13c)}

Chemical formula: $\mathrm{C}_{28} \mathrm{H}_{28} \mathrm{ClN}_{3} \mathrm{O}_{3}$; yield: $81 \%$; white solid; mp: 79-81 ${ }^{\circ} \mathrm{C}$; ${ }^{1} \mathrm{H}-\mathrm{NMR}\left(400 \mathrm{MHz}, \mathrm{CDCl}_{3}\right)$ $\delta 12.92(\mathrm{~s}, 1 \mathrm{H}), 8.01(\mathrm{~s}, 1 \mathrm{H}), 7.74(\mathrm{~d}, J=9.07 \mathrm{~Hz}, 1 \mathrm{H})$, $7.68(\mathrm{~d}, J=8.82 \mathrm{~Hz}, 2 \mathrm{H}), 7.50(\mathrm{~d}, J=8.85 \mathrm{~Hz}, 2 \mathrm{H}), 7.19$ $(\mathrm{d}, J=8.04 \mathrm{~Hz}, 2 \mathrm{H}), 7.08(\mathrm{~d}, J=8.04 \mathrm{~Hz}, 2 \mathrm{H}), 6.53(\mathrm{~d}$, $J=2.48 \mathrm{~Hz}, 1 \mathrm{H}), 6.45(\mathrm{dd}, J=8.99,2.51 \mathrm{~Hz}, 1 \mathrm{H}), 5.28$ $(\mathrm{s}, 2 \mathrm{H}), 4.61(\mathrm{q}, J=6.83 \mathrm{~Hz}, 1 \mathrm{H}), 2.41(\mathrm{~d}, J=7.17 \mathrm{~Hz}$, $2 \mathrm{H}), 1.87-1.77(\mathrm{~m}, 1 \mathrm{H}), 1.52(\mathrm{~d}, J=6.84 \mathrm{~Hz}, 3 \mathrm{H}), 0.87(\mathrm{~d}$, $J=6.53 \mathrm{~Hz}, 6 \mathrm{H}) ;{ }^{13} \mathrm{C}-\mathrm{NMR}\left(126 \mathrm{MHz}, \mathrm{CDCl}_{3}\right) \delta 205.1$, $166.2,164.5,144.7,141.1,139.1,135.9,135.4,132.9,130.6$ (2C), 130.4 (2C), 127.9, 122.5 (2C), 121.7, 114.1, 108.3, 103.0, 63.1, 47.9, 46.3, 31.5, 23.8 (2C), 20.7; LRMS: (ES+) $m / z=490[\mathrm{M}+1]$; HPLC $96.19 \%$, column: X-BRIDGE C-18 (150X4.6 mm), mobile phase A: $0.1 \%$ farmic acid in water, mobile phase $\mathrm{B}$ : acetonitrile, gradient $(\mathrm{T} / \% \mathrm{~B})$ : 0/20, 3/20, 12/95, 23/95, 25/20, 30/20; flow rate: $1.0 \mathrm{~mL} /$ min.

\section{1-(4-((1-(Sec-butyl)-1H-1,2,3-triazol-4-yl) methoxy)-2-hydroxyphenyl)-2-(4-isobutylphenyl) propan-1-one (13d)}

Chemical formula: $\mathrm{C}_{26} \mathrm{H}_{33} \mathrm{~N}_{3} \mathrm{O}_{3}$; yield: 79 \%; white solid; mp: 89-91 ${ }^{\circ} \mathrm{C} ;{ }^{1} \mathrm{H}-\mathrm{NMR}\left(400 \mathrm{MHz}, \mathrm{CDCl}_{3}\right) \delta 12.91$ (s, $1 \mathrm{H}), 7.73(\mathrm{~d}, J=8.77 \mathrm{~Hz}, 1 \mathrm{H}), 7.61(\mathrm{~s}, 1 \mathrm{H}), 7.19(\mathrm{~d}$, $J=7.85 \mathrm{~Hz}, 2 \mathrm{H}), 7.08(\mathrm{~d}, J=7.82 \mathrm{~Hz}, 2 \mathrm{H}), 6.50(\mathrm{~s}, 1 \mathrm{H})$, $6.45(\mathrm{~d}, J=8.68 \mathrm{~Hz}, 1 \mathrm{H}), 5.19(\mathrm{~s}, 2 \mathrm{H}), 4.69-4.52(\mathrm{~m}, 2 \mathrm{H})$, $2.41(\mathrm{~d}, J=7.12 \mathrm{~Hz}, 2 \mathrm{H}), 1.98-1.77(\mathrm{~m}, 3 \mathrm{H}), 1.57(\mathrm{~d}$, $J=6.41 \mathrm{~Hz}, 3 \mathrm{H}), 1.51(\mathrm{~d}, J=6.78 \mathrm{~Hz}, 3 \mathrm{H}), 0.91-0.83(\mathrm{~m}$, 9H); ${ }^{13} \mathrm{C}$-NMR $\left(100 \mathrm{MHz}, \mathrm{CDCl}_{3}\right) \delta 205.0,165.8,164.4$, 142.2, 140.5, 138.6, 132.2, 129.7 (2C), 127.2 (2C), 122.4, 113.2, 107.5, 102.2, 62.3, 59.1, 46.5, 45.0, 30.3, 30.1, 22.4 (2C), 20.8, 19.2, 10.4; LRMS: (ES+) $m / z=436[\mathrm{M}+1]$, $458[\mathrm{M}+\mathrm{Na}]$.

\section{1-(4-((1-Butyl-1H-1,2,3-triazol-4-yl) \\ methoxy)-2-hydroxyphenyl)-2-(4-isobutylphenyl) \\ propan-1-one (13e)}

Chemical formula: $\mathrm{C}_{26} \mathrm{H}_{33} \mathrm{~N}_{3} \mathrm{O}_{3}$; yield: $91 \%$; white solid; mp: $89-91{ }^{\circ} \mathrm{C} ;{ }^{1} \mathrm{H}-\mathrm{NMR}\left(400 \mathrm{MHz}, \mathrm{CDCl}_{3}\right) \delta 12.91$ (s, $1 \mathrm{H}), 7.72(\mathrm{~d}, J=9.03 \mathrm{~Hz}, 1 \mathrm{H}), 7.58(\mathrm{~s}, 1 \mathrm{H}), 7.19(\mathrm{~d}$, $J=7.94 \mathrm{~Hz}, 2 \mathrm{H}), 7.08(\mathrm{~d}, J=7.91 \mathrm{~Hz}, 2 \mathrm{H}), 6.49(\mathrm{~d}$, $J=2.24 \mathrm{~Hz}, 1 \mathrm{H}), 6.43(\mathrm{dd}, J=8.98,2.29 \mathrm{~Hz}, 1 \mathrm{H}), 5.18$ $(\mathrm{s}, 2 \mathrm{H}), 4.61(\mathrm{q}, J=6.74 \mathrm{~Hz}, 1 \mathrm{H}), 4.35(\mathrm{t}, J=7.23 \mathrm{~Hz}$, $2 \mathrm{H}), 2.41(\mathrm{~d}, J=7.14 \mathrm{~Hz}, 2 \mathrm{H}), 1.92-1.78(\mathrm{~m}, 3 \mathrm{H}), 1.51(\mathrm{~d}$, $J=6.82 \mathrm{~Hz}, 3 \mathrm{H}), 1.40-1.30(\mathrm{~m}, 2 \mathrm{H}), 0.95(\mathrm{t}, J=7.35 \mathrm{~Hz}$, $3 \mathrm{H}), 0.87$ (d, $J=6.56 \mathrm{~Hz}, 6 \mathrm{H}) ;{ }^{13} \mathrm{C}-\mathrm{NMR}(101 \mathrm{MHz}$, 
$\left.\mathrm{CDCl}_{3}\right) \delta 205.0,165.8,164.3,143.0,140.5,138.6,132.2$, 129.7 (2C), 127.2 (2C), 122.6, 113.2, 107.6, 102.2, 62.1, 50.2, 46.5, 45.0, 32.2, 30.1, 22.4 (2C) 19.7, 19.2, 13.4; LRMS: $(\mathrm{ES}+) m / z=436[\mathrm{M}+1], 458[\mathrm{M}+\mathrm{Na}]$; HPLC $99.31 \%$, column: phenomenex luna C8 (2) (250X4.6 mm), mobile phase: $90 \%$ acetonitrile in $0.1 \%$ formic acid, flow rate: $1.0 \mathrm{~mL} / \mathrm{min}$.

\section{1-(2-Hydroxy-4-((1-isobutyl-1H-1,2,3-triazol-4-yl)methoxy) phenyl)-2-(4-isobutylphenyl)propan-1-one (13f)}

Chemical formula: $\mathrm{C}_{26} \mathrm{H}_{33} \mathrm{~N}_{3} \mathrm{O}_{3}$; yield: $86 \%$; white solid; mp: 97-99 ${ }^{\circ} \mathrm{C}$; ${ }^{1} \mathrm{H}-\mathrm{NMR}\left(400 \mathrm{MHz}, \mathrm{CDCl}_{3}\right) \delta 12.89$ (s, $1 \mathrm{H}), 7.80-7.48(\mathrm{~m}, 2 \mathrm{H}), 7.30-7.00(\mathrm{~m}, 4 \mathrm{H}), 6.58-6.35$ $(\mathrm{m}, 2 \mathrm{H}), 5.19(\mathrm{~d}, J=0.52 \mathrm{~Hz}, 2 \mathrm{H}), 4.72-4.54(\mathrm{~m}, 1 \mathrm{H})$, 4.25-4.08 (m, 2H), 2.52-2.11 (m, 3H), 1.81-1.51 (m, 5H), 1.09-0.73 (m, 12H); ${ }^{13} \mathrm{C}-\mathrm{NMR}\left(101 \mathrm{MHz}, \mathrm{CDCl}_{3}\right) \delta$ 205.0, 165.8, 164.3, 142.9, 140.5, 138.6, 132.2, 129.7 (2C), 127.2 (2C), 123.1, 113.2, 107.6, 102.2, 62.1, 57.6, 46.5, 45.0, 30.0, 29.6, 22.3 (2C), 19.8 (2C), 19.2; LRMS: (ES+) $m / z=436[\mathrm{M}+1], 458[\mathrm{M}+\mathrm{Na}]$; HPLC $99.32 \%$, column: phenomenex luna C8 (2) (250X4.6 mm), mobile phase: $90 \%$ acetonitrile in $0.1 \%$ formic acid, flow rate: $1.0 \mathrm{~mL} / \mathrm{min}$.

\section{1-(2-Hydroxy-4-((1-phenyl-1H-1,2,3-triazol-4-yl)methoxy) phenyl)-2-(4-isobutylphenyl)propan-1-one (13g)}

Chemical formula: $\mathrm{C}_{28} \mathrm{H}_{29} \mathrm{~N}_{3} \mathrm{O}_{3}$; yield: $96 \%$; white solid; mp: $138-140{ }^{\circ} \mathrm{C} ;{ }^{1} \mathrm{H}-\mathrm{NMR}\left(500 \mathrm{MHz}, \mathrm{CDCl}_{3}\right) \delta 12.91(\mathrm{~s}$, $1 \mathrm{H}), 8.04(\mathrm{~s}, 1 \mathrm{H}), 7.76-7.71(\mathrm{~m}, 3 \mathrm{H}), 7.53(\mathrm{t}, J=7.77 \mathrm{~Hz}$, $2 \mathrm{H}), 7.45(\mathrm{t}, J=7.40 \mathrm{~Hz}, 1 \mathrm{H}), 7.21(\mathrm{~d}, J=8.02 \mathrm{~Hz}, 2 \mathrm{H})$, $7.09(\mathrm{~d}, J=8.00 \mathrm{~Hz}, 2 \mathrm{H}), 6.54(\mathrm{~d}, J=2.46 \mathrm{~Hz}, 1 \mathrm{H})$,), $6.47(\mathrm{dd}, J=8.99,2.48 \mathrm{~Hz}, 1 \mathrm{H}), 5.29(\mathrm{~s}, 2 \mathrm{H}), 4.63$ (q, $J=6.81 \mathrm{~Hz}, 1 \mathrm{H}), 2.43(\mathrm{~d}, J=7.16 \mathrm{~Hz}, 2 \mathrm{H}), 1.87-1.79$ $(\mathrm{m}, 1 \mathrm{H}), 1.54(\mathrm{~d}, J=6.84 \mathrm{~Hz}, 3 \mathrm{H}), 0.89(\mathrm{~d}, J=6.59 \mathrm{~Hz}$, $6 \mathrm{H}) ;{ }^{13} \mathrm{C}-\mathrm{NMR}\left(126 \mathrm{MHz}, \mathrm{CDCl}_{3}\right) \delta$ 205.1, 166.3, 164.6, $144.4,141.1,139.1,137.4,132.9,130.4$ (2C), 130.3 (2C), 129.6, 127.9 (2C), 121.8, 121.3 (2C), 114.1, 108.3, 103.1, 63.1, 47.8, 46.3, 31.5, 23.8 (2C), 20.7; LRMS: (ES+) $m / z=456[\mathrm{M}+1], 478[\mathrm{M}+\mathrm{Na}]$; HPLC $99.28 \%$, column: X-BRIDGE C-18 (150X4.6 mm), mobile phase A: $0.1 \%$ farmic acid in water, mobile phase $\mathrm{B}$ : acetonitrile, gradient (T/\%B): 0/20, 3/20, 12/95, 23/95, 25/20, 30/20; flow rate: $1.0 \mathrm{~mL} / \mathrm{min}$.

\section{1-(2-Hydroxy-4-((1-(p-tolyl)-1H-1,2,3-triazol-4-yl)methoxy) phenyl)-2-(4-isobutylphenyl)propan-1-one (13h)}

Chemical formula: $\mathrm{C}_{29} \mathrm{H}_{31} \mathrm{~N}_{3} \mathrm{O}_{3}$; yield: $83 \%$; white solid; mp: $126-128{ }^{\circ} \mathrm{C}$; ${ }^{1} \mathrm{H}-\mathrm{NMR}\left(400 \mathrm{MHz}, \mathrm{CDCl}_{3}\right) \delta 12.92$ (s, $1 \mathrm{H}), 7.99(\mathrm{~s}, 1 \mathrm{H}), 7.77-7.69(\mathrm{~m}, 2 \mathrm{H}), 7.59(\mathrm{~d}, J=8.44 \mathrm{~Hz}$, $1 \mathrm{H}), 7.31(\mathrm{~d}, J=8.15 \mathrm{~Hz}, 2 \mathrm{H}), 7.19(\mathrm{~d}, J=8.07 \mathrm{~Hz}$, $2 \mathrm{H}), 7.08(\mathrm{~d}, J=8.06 \mathrm{~Hz}, 2 \mathrm{H}), 6.53(\mathrm{~d}, J=2.43 \mathrm{~Hz}$, $1 \mathrm{H}), 6.46(\mathrm{dd}, J=9.01,2.50 \mathrm{~Hz}, 1 \mathrm{H}), 5.27(\mathrm{~s}, 2 \mathrm{H}), 4.62$ $(\mathrm{q}, J=6.84 \mathrm{~Hz}, 1 \mathrm{H}), 2.43-2.39(\mathrm{~m}, 5 \mathrm{H}), 1.85-1.77$ $(\mathrm{m}, 1 \mathrm{H}), 1.51(\mathrm{~d}, J=6.85 \mathrm{~Hz}, 3 \mathrm{H}), 0.87(\mathrm{~d}, J=6.59 \mathrm{~Hz}$, 6H); ${ }^{13} \mathrm{C}$-NMR (126 MHz, $\mathrm{CDCl}_{3}$ ) $\delta$ 205.1, 166.3, 164.6, $144.2,141.1,139.7,139.2,132.9,130.9$ (2C), 130.3 (2C), 127.9 (2C), 121.8, 121.3, 121.2 (2C), 114.1, 108.4, 103.1, 63.2, 47.8, 46.3, 31.5, 23.8 (2C), 22.5, 20.7; LRMS: (ES+) $m / z=470[\mathrm{M}+1], 492[\mathrm{M}+\mathrm{Na}]$; HPLC $98.88 \%$, column: X-BRIDGE C-18 (150X4.6 mm), mobile phase A: $0.1 \%$ farmic acid in water, mobile phase B: acetonitrile, gradient (T/\%B): 0/20, 3/20, 12/95, 23/95, 25/20, 30/20; flow rate: $1.0 \mathrm{~mL} / \mathrm{min}$.

\section{1-(4-((1-(3-Chlorophenyl)-1H-1,2,3-triazol-4-yl) methoxy)-2-hydroxyphenyl)-2-(4-isobutylphenyl) propan-1-one (13i)}

Chemical formula: $\mathrm{C}_{28} \mathrm{H}_{28} \mathrm{ClN}_{3} \mathrm{O}_{3}$; yield: $89 \%$; white solid; mp: $118-120{ }^{\circ} \mathrm{C}$; ${ }^{1} \mathrm{H}-\mathrm{NMR}\left(400 \mathrm{MHz}, \mathrm{CDCl}_{3}\right) \delta$ $12.92(\mathrm{~s}, 1 \mathrm{H}), 8.04(\mathrm{~s}, 1 \mathrm{H}), 7.78(\mathrm{t}, J=1.8 \mathrm{~Hz}, 1 \mathrm{H}), 7.74$ $(\mathrm{d}, J=9.1 \mathrm{~Hz}, 1 \mathrm{H}), 7.65-7.61(\mathrm{~m}, 1 \mathrm{H}), 7.48-7.40(\mathrm{~m}$, $2 \mathrm{H}), 7.19(\mathrm{~d}, J=8.1 \mathrm{~Hz}, 2 \mathrm{H}), 7.08(\mathrm{~d}, J=8.0 \mathrm{~Hz}, 2 \mathrm{H})$, $6.52(\mathrm{~d}, J=2.5 \mathrm{~Hz}, 1 \mathrm{H}), 6.45(\mathrm{dd}, J=9.0,2.5 \mathrm{~Hz}, 1 \mathrm{H})$, $5.27(\mathrm{~s}, 2 \mathrm{H}), 4.62(\mathrm{q}, J=6.8 \mathrm{~Hz}, 1 \mathrm{H}), 2.41(\mathrm{~d}, J=7.1 \mathrm{~Hz}$, $2 \mathrm{H}), 1.86-1.76(\mathrm{~m}, 1 \mathrm{H}), 1.51(\mathrm{~d}, J=6.8 \mathrm{~Hz}, 3 \mathrm{H}), 0.87(\mathrm{~d}$, $J=6.6 \mathrm{~Hz}, 6 \mathrm{H}) ;{ }^{13} \mathrm{C}-\mathrm{NMR}\left(126 \mathrm{MHz}, \mathrm{CDCl}_{3}\right) \delta 205.1$, $166.2,164.5,144.7,141.1,139.1,138.2,136.2,132.9$, $131.5,130.4$ (2C), 129.7, 127.9 (2C), 121.8, 121.5, 119.2, 114.1, 108.3, 103.0, 63.0, 47.8, 46.2, 31.5, 23.8 (2C), 20.7; LRMS: $(\mathrm{ES}+) m / z=490[\mathrm{M}+1], 512[\mathrm{M}+\mathrm{Na}]$; HPLC $98.70 \%$, column: X-BRIDGE C-18 (150X4.6 mm), mobile phase A: $0.1 \%$ farmic acid in water, mobile phase B: acetonitrile, gradient (T/\%B): 0/20, 3/20, 12/95, 23/95, 25/20, 30/20; flow rate: $1.0 \mathrm{~mL} / \mathrm{min}$.

\section{1-(4-((1-Dodecyl-1H-1,2,3-triazol-4-yl)}

\section{methoxy)-2-hydroxyphenyl)-2-(4-isobutylphenyl)}

propan-1-one (13j)

Chemical formula: $\mathrm{C}_{34} \mathrm{H}_{49} \mathrm{~N}_{3} \mathrm{O}_{3}$; yield: $95 \%$; white solid; mp: 69-71 ${ }^{\circ} \mathrm{C}$; ${ }^{1} \mathrm{H}-\mathrm{NMR}\left(400 \mathrm{MHz}, \mathrm{CDCl}_{3}\right) \delta 12.92$ (s, 1H), $7.72(\mathrm{~d}, J=9.05 \mathrm{~Hz}, 1 \mathrm{H}), 7.58(\mathrm{~s}, 1 \mathrm{H}), 7.19$ (d, $J=7.92 \mathrm{~Hz}, 2 \mathrm{H}), 7.08(\mathrm{~d}, J=7.89 \mathrm{~Hz}, 2 \mathrm{H}), 6.49(\mathrm{~d}$, $J=2.18 \mathrm{~Hz}, 1 \mathrm{H}), 6.43(\mathrm{dd}, J=8.98,2.21 \mathrm{~Hz}, 1 \mathrm{H}), 5.18$ $(\mathrm{s}, 2 \mathrm{H}), 4.61(\mathrm{q}, J=6.72 \mathrm{~Hz}, 1 \mathrm{H}), 4.33(\mathrm{t}, J=7.24 \mathrm{~Hz}$, $2 \mathrm{H}), 2.41(\mathrm{~d}, J=7.14 \mathrm{~Hz}, 2 \mathrm{H}), 1.93-1.78(\mathrm{~m}, 3 \mathrm{H}), 1.51$ $(\mathrm{d}, J=6.80 \mathrm{~Hz}, 3 \mathrm{H}), 1.33-1.23(\mathrm{~m}, 19 \mathrm{H}), 0.90-0.85(\mathrm{~m}$, 9H); ${ }^{13} \mathrm{C}-\mathrm{NMR}\left(101 \mathrm{MHz}, \mathrm{CDCl}_{3}\right) \delta$ 205.0, 165.8, 164.3, 143.0, 140.5, 138.6, 132.2, 129.7 (2C), 127.2 (2C), 122.6, 113.2, 107.6, 102.2, 62.1, 50.5, 46.5, 45.0, 31.9, 30.2, 30.1, 29.6 (2C), 29.5, 29.3, 29.3, 28.9, 26.5, 22.7, 22.4, 22.4, 19.2, 14.1; LRMS: $(\mathrm{ES}+) m / z=548[\mathrm{M}+1], 570[\mathrm{M}+\mathrm{Na}]$; HPLC 98.21 \%, column: phenomenex luna C8 (2) (250X4.6 mm), mobile phase: $90 \%$ acetonitrile in $0.1 \%$ formic acid, flow rate: $1.0 \mathrm{~mL} / \mathrm{min}$. 
1-(2-Hydroxy-4-((1-(3-nitrophenyl)-1H-1,2,3-triazol-4-yl) methoxy)phenyl)-2-(4-isobutylphenyl)propan-1-one (13k) Chemical formula: $\mathrm{C}_{28} \mathrm{H}_{28} \mathrm{~N}_{4} \mathrm{O}_{5}$; yield: $81 \%$; yellow solid; mp: $146-148{ }^{\circ} \mathrm{C}$; ${ }^{1} \mathrm{H}-\mathrm{NMR}\left(400 \mathrm{MHz}, \mathrm{CDCl}_{3}\right) \delta 12.92$ (s, $1 \mathrm{H}), 8.60(\mathrm{~s}, 1 \mathrm{H}), 8.31(\mathrm{~d}, J=8.11 \mathrm{~Hz}, 1 \mathrm{H}), 8.18(\mathrm{~d}$, $J=6.46 \mathrm{~Hz}, 2 \mathrm{H}), 7.80-7.70(\mathrm{~m}, 2 \mathrm{H}), 7.19(\mathrm{~d}, J=7.90 \mathrm{~Hz}$, $2 \mathrm{H}), 7.08(\mathrm{~d}, J=7.88 \mathrm{~Hz}, 2 \mathrm{H}), 6.52(\mathrm{~d}, J=2.20 \mathrm{~Hz}, 1 \mathrm{H})$, $6.46(\mathrm{dd}, J=8.96,2.24 \mathrm{~Hz}, 1 \mathrm{H}), 5.30(\mathrm{~s}, 2 \mathrm{H}), 4.62(\mathrm{q}$, $J=6.67 \mathrm{~Hz}, 1 \mathrm{H}), 2.41(\mathrm{~d}, J=7.13 \mathrm{~Hz}, 2 \mathrm{H}), 1.87-1.76(\mathrm{~m}$, $1 \mathrm{H}), 1.51(\mathrm{~d}, J=6.79 \mathrm{~Hz}, 3 \mathrm{H}), 0.87(\mathrm{~d}, J=6.55 \mathrm{~Hz}, 6 \mathrm{H})$; ${ }^{13} \mathrm{C}-\mathrm{NMR}\left(101 \mathrm{MHz}, \mathrm{CDCl}_{3}\right) \delta 205.1,165.8,164.0,148.9$, 144.7, 140.6, 138.5, 137.5, 132.3, 131.0, 129.7 (2C), 127.2 (2C), 126.0, 123.4, 121.1, 115.3, 113.4, 107.5, 102.2, 61.8, 46.6, 45.0, 30.1, 22.3 (2C), 19.2; LRMS: (ES+) $\mathrm{m} / z=501$ $[\mathrm{M}+1], 523[\mathrm{M}+\mathrm{Na}]$; HPLC $99.69 \%$, column: phenomenex luna C8 (2) (250X4.6 mm), mobile phase: $90 \%$ acetonitrile in $0.1 \%$ formic acid, flow rate: $1.0 \mathrm{~mL} / \mathrm{min}$.

\section{1-(2-Hydroxy-4-((1-(4-nitrophenyl)-1H-1,2,3-triazol-4-yl)} methoxy)phenyl)-2-(4-isobutylphenyl)propan-1-one (13I)

Chemical formula: $\mathrm{C}_{28} \mathrm{H}_{28} \mathrm{~N}_{4} \mathrm{O}_{5}$; yield: $77 \%$; yellow solid; mp: $167-169{ }^{\circ} \mathrm{C}$; ${ }^{1} \mathrm{H}-\mathrm{NMR}\left(400 \mathrm{MHz}, \mathrm{CDCl}_{3}\right.$ ) $\delta 12.93(\mathrm{~s}, 1 \mathrm{H}), 8.42(\mathrm{~d}, J=9.0 \mathrm{~Hz}, 2 \mathrm{H}), 8.19(\mathrm{~s}, 1 \mathrm{H})$, 7.99 (d, $J=9.0 \mathrm{~Hz}, 2 \mathrm{H}), 7.77$ (d, $J=9.0 \mathrm{~Hz}, 1 \mathrm{H}), 7.21$ $(\mathrm{d}, J=8.0 \mathrm{~Hz}, 2 \mathrm{H}), 7.10(\mathrm{~d}, J=8.0 \mathrm{~Hz}, 2 \mathrm{H}), 6.53(\mathrm{~d}$, $J=2.4 \mathrm{~Hz}, 1 \mathrm{H}), 6.46(\mathrm{dd}, J=8.9,2.4 \mathrm{~Hz}, 1 \mathrm{H}), 5.31(\mathrm{~s}, 2 \mathrm{H})$, $4.63(\mathrm{q}, J=6.8 \mathrm{~Hz}, 1 \mathrm{H}), 2.43(\mathrm{~d}, J=7.1 \mathrm{~Hz}, 2 \mathrm{H}), 1.88-$ $1.78(\mathrm{~m}, 1 \mathrm{H}), 1.53(\mathrm{~d}, J=6.8 \mathrm{~Hz}, 3 \mathrm{H}), 0.89(\mathrm{~d}, J=6.6 \mathrm{~Hz}$, $6 \mathrm{H}) ;{ }^{13} \mathrm{C}-\mathrm{NMR}\left(101 \mathrm{MHz}, \mathrm{CDCl}_{3}\right) \delta 205.1,165.8,163.9$, $147.3,144.9,140.9,140.6,138.5,132.3,129.7$ (2C), 127.2 (2C), $125.5(2 \mathrm{C}), 120.9,120.6(2 \mathrm{C}), 113.5,107.4,102.2$, 61.8, 46.6, 45.0, 30.1, 22.4, 22.3 (2C), 19.2; LRMS: (ES+) $m / z=501[\mathrm{M}+1]$; HPLC $99.87 \%$, column: phenomenex luna C8 (2) (250X4.6 mm), mobile phase: $90 \%$ acetonitrile in $0.1 \%$ formic acid, flow rate: $1.0 \mathrm{~mL} / \mathrm{min}$.

\section{1-(4-((1-Cyclohexyl-1H-1,2,3-triazol-4-yl) methoxy)-2-hydroxyphenyl)-2-(4-isobutylphenyl) propan-1-one (13m)}

Chemical formula: $\mathrm{C}_{28} \mathrm{H}_{35} \mathrm{~N}_{3} \mathrm{O}_{3}$; yield: $89 \%$; white solid; mp: $118-120{ }^{\circ} \mathrm{C}$; ${ }^{1} \mathrm{H}-\mathrm{NMR}\left(400 \mathrm{MHz}, \mathrm{CDCl}_{3}\right) \delta 12.92$ (s, 1H), $7.73(\mathrm{~d}, J=9.10 \mathrm{~Hz}, 1 \mathrm{H}), 7.60(\mathrm{~s}, 1 \mathrm{H}), 7.19$ (d, $J=8.08 \mathrm{~Hz}, 2 \mathrm{H}), 7.08(\mathrm{~d}, J=8.08 \mathrm{~Hz}, 2 \mathrm{H}), 6.50(\mathrm{~d}$, $J=2.50 \mathrm{~Hz}, 1 \mathrm{H}), 6.44(\mathrm{dd}, J=9.00,2.53 \mathrm{~Hz}, 1 \mathrm{H}), 5.18(\mathrm{~s}$, $2 \mathrm{H}), 4.61(\mathrm{q}, J=6.86 \mathrm{~Hz}, 1 \mathrm{H}), 4.45(\mathrm{tt}, J=11.85,3.85 \mathrm{~Hz}$, $1 \mathrm{H}), 2.41(\mathrm{~d}, J=7.18 \mathrm{~Hz}, 2 \mathrm{H}), 2.25-2.17(\mathrm{~m}, 2 \mathrm{H})$, 1.97-1.88 (m, 2H), $1.77(\mathrm{~m}, 3 \mathrm{H}), 1.51(\mathrm{~d}, J=6.87 \mathrm{~Hz}$, $3 \mathrm{H}), 1.49-1.39(\mathrm{~m}, 2 \mathrm{H}), 1.33-1.23(\mathrm{~m}, 2 \mathrm{H}), 0.87(\mathrm{~d}$, $J=6.61 \mathrm{~Hz}, 6 \mathrm{H}) ;{ }^{13} \mathrm{C}-\mathrm{NMR}\left(126 \mathrm{MHz}, \mathrm{CDCl}_{3}\right) \delta 205.1$, 166.2, 164.8, 143.1, 141.1, 139.2, 132.8, 130.3 (2C), 127.9 (2C), 121.3, 114.0, 108.4, 103.0, 63.3, 61.4, 47.8, 46.3, 34.9 (2C), 31.5, 26.5 (2C), 26.5, 23.8 (2C), 20.7; LRMS: (ES+) $m / z=462[\mathrm{M}+1]$; HPLC $99.89 \%$, column: phenomenex luna C8 (2) (250X4.6 mm), mobile phase: $90 \%$ acetonitrile in $0.1 \%$ formic acid, flow rate: $1.0 \mathrm{~mL} / \mathrm{min}$.

\section{1-(4-((1-Cyclopentyl-1H-1,2,3-triazol-4-yl)}

methoxy)-2-hydroxyphenyl)-2-(4-isobutylphenyl)

propan-1-one (13n)

Chemical formula: $\mathrm{C}_{27} \mathrm{H}_{33} \mathrm{~N}_{3} \mathrm{O}_{3}$; yield: $82 \%$; white solid; mp: $130-132{ }^{\circ} \mathrm{C}$; ${ }^{1} \mathrm{H}-\mathrm{NMR}\left(400 \mathrm{MHz}, \mathrm{CDCl}_{3}\right) \delta$ 12.92 (s, 1H), 7.73 (d, $J=8.7 \mathrm{~Hz}, 1 \mathrm{H}), 7.60$ (s, 1H), 7.19 $(\mathrm{d}, J=8.0 \mathrm{~Hz}, 2 \mathrm{H}), 7.08(\mathrm{~d}, J=8.0 \mathrm{~Hz}, 2 \mathrm{H}), 6.50(\mathrm{~d}$, $J=2.5 \mathrm{~Hz}, 1 \mathrm{H}), 6.44(\mathrm{dd}, J=8.6,2.5 \mathrm{~Hz}, 1 \mathrm{H}), 5.17(\mathrm{~s}$, $2 \mathrm{H}), 4.96-4.88(\mathrm{~m}, 1 \mathrm{H}), 4.61(\mathrm{q}, J=6.84 \mathrm{~Hz}, 1 \mathrm{H}), 2.41(\mathrm{~d}$, $J=7.2 \mathrm{~Hz}, 2 \mathrm{H}), 2.31-2.21(\mathrm{~m}, 2 \mathrm{H}), 2.09-1.99$ (m, 2H), $1.96-1.86(\mathrm{~m}, 2 \mathrm{H}), 1.84-1.74(\mathrm{~m}, 3 \mathrm{H}), 1.51(\mathrm{~d}, J=6.8 \mathrm{~Hz}$, $3 \mathrm{H}), 0.87(\mathrm{~d}, J=6.5 \mathrm{~Hz}, 6 \mathrm{H})$; LRMS: $(\mathrm{ES}+) \mathrm{m} / z=448$ $[\mathrm{M}+1], 470[\mathrm{M}+\mathrm{Na}]$; HPLC $99.37 \%$, column: phenomenex luna C8 (2) (250X4.6 mm), mobile phase: $90 \%$ acetonitrile in $0.1 \%$ formic acid, flow rate: $1.0 \mathrm{~mL} / \mathrm{min}$.

\section{1-(2-Hydroxy-4-((1-(4-nitrobenzyl)-1H-1,2,3-triazol-4-yl)} methoxy)phenyl)-2-(4-isobutylphenyl)propan-1-one (13o)

Chemical formula: $\mathrm{C}_{29} \mathrm{H}_{30} \mathrm{~N}_{4} \mathrm{O}_{5}$; yield: $90 \%$; white solid; mp: $150-152{ }^{\circ} \mathrm{C} ;{ }^{1} \mathrm{H}-\mathrm{NMR}\left(400 \mathrm{MHz}, \mathrm{CDCl}_{3}\right) \delta 12.91$ (s, $1 \mathrm{H}), 8.24(\mathrm{~d}, J=8.4 \mathrm{~Hz}, 2 \mathrm{H}), 7.73(\mathrm{~d}, J=9.07 \mathrm{~Hz}$, $1 \mathrm{H}), 7.61(\mathrm{~s}, J=3.97 \mathrm{~Hz}, 1 \mathrm{H}), 7.45-7.39(\mathrm{~m}, 2 \mathrm{H}), 7.28$ (s, 1H), 7.19 (d, J = 7.30 Hz, 2H), $7.10(\mathrm{~d}, 1 \mathrm{H}), 6.49$ (d, $J=2.49 \mathrm{~Hz}, 1 \mathrm{H}), 6.42(\mathrm{dd}, J=8.98,2.53 \mathrm{~Hz}, 1 \mathrm{H}), 5.66$ $(\mathrm{s}, J=3.05 \mathrm{~Hz}, 2 \mathrm{H}), 5.21(\mathrm{~s}, J=3.99 \mathrm{~Hz}, 2 \mathrm{H}), 4.63(\mathrm{q}$, $J=6.82 \mathrm{~Hz}, 1 \mathrm{H}), 2.44(\mathrm{~d}, J=6.00 \mathrm{~Hz}, 2 \mathrm{H}), 1.89-1.80(\mathrm{~m}$, $1 \mathrm{H}), 1.53(\mathrm{~d}, J=8.49 \mathrm{~Hz}, 3 \mathrm{H}), 0.90(\mathrm{~d}, J=6.42 \mathrm{~Hz}, 6 \mathrm{H})$; ${ }^{13} \mathrm{C}-\mathrm{NMR}\left(100 \mathrm{MHz}, \mathrm{CDCl}_{3}\right) \delta 205.18,166.37,164.60$, $148.83,144.88,142.04,141.33,139.30,133.07,130.5(2 \mathrm{C})$, 129.5 (2C), $128.0(2 \mathrm{C}), 125.2(2 \mathrm{C}), 123.88,114.35,108.58$, 103.24, 63.43, 54.77, 48.21, 46.61, 31.88, 24.21 (2C), 21.06; LRMS: $(\mathrm{ES}+) m / z=515[\mathrm{M}+1], 537[\mathrm{M}+\mathrm{Na}]$; HPLC $99.68 \%$, column: phenomenex luna C8 (2) (250X4.6 mm), mobile phase: $90 \%$ acetonitrile in $0.1 \%$ formic acid, flow rate: $1.0 \mathrm{~mL} / \mathrm{min}$.

\section{1-(4-((1-(4-Bromophenyl)-1H-1,2,3-triazol-4-yl) methoxy)-2-hydroxyphenyl)-2-(4-isobutylphenyl) propan-1-one (13p)}

Chemical formula: $\mathrm{C}_{28} \mathrm{H}_{28} \mathrm{BrN}_{3} \mathrm{O}_{3}$; yield: $86 \%$; white solid; mp: $133-135{ }^{\circ} \mathrm{C}$; ${ }^{1} \mathrm{H}-\mathrm{NMR}\left(400 \mathrm{MHz}, \mathrm{CDCl}_{3}\right) \delta$ $12.92(\mathrm{~s}, 1 \mathrm{H}), 8.02(\mathrm{~s}, 1 \mathrm{H}), 7.74(\mathrm{~d}, J=9.07 \mathrm{~Hz}, 1 \mathrm{H}), 7.63$ $(\mathrm{m}, J=8.98,2.18 \mathrm{~Hz}, 4 \mathrm{H}), 7.19(\mathrm{~d}, J=8.02 \mathrm{~Hz}, 2 \mathrm{H}), 7.08$ $(\mathrm{d}, J=8.00 \mathrm{~Hz}, 2 \mathrm{H}), 6.52$ (d, $J=2.44 \mathrm{~Hz}, 1 \mathrm{H}), 6.45$ (dd, $J=8.99,2.47 \mathrm{~Hz}, 1 \mathrm{H}), 5.27(\mathrm{~s}, 2 \mathrm{H}), 4.61(\mathrm{q}, J=6.81 \mathrm{~Hz}$, $1 \mathrm{H}), 2.41(\mathrm{~d}, J=7.16 \mathrm{~Hz}, 2 \mathrm{H}), 1.82-1.79(\mathrm{~m}, 1 \mathrm{H}), 1.51$ $(\mathrm{d}, J=6.84 \mathrm{~Hz}, 3 \mathrm{H}), 0.87(\mathrm{~d}, J=6.59 \mathrm{~Hz}, 6 \mathrm{H}) ;{ }^{13} \mathrm{C}-\mathrm{NMR}$ $\left(101 \mathrm{MHz}, \mathrm{CDCl}_{3}\right) \delta$ 205.2, 166.3, 164.6, 144.9, 141.3, $139.3,136.5,133.7$ (2C), 133.1, 130.5 (2C), 128.1 (2C), 123.6, 122.9 (2C), 121.8, 114.3, 108.5, 103.3, 63.3, 48.2, 
46.6, 31.9, 24.2 (2C), 21.0; LRMS: (ES+) $\mathrm{m} / z=535$ $[\mathrm{M}+1]$.

\section{1-(4-((1-(2-Chlorophenyl)-1H-1,2,3-triazol-4-yl) methoxy)-2-hydroxyphenyl)-2-(4-isobutylphenyl) propan-1-one (13q)}

Chemical formula: $\mathrm{C}_{28} \mathrm{H}_{28} \mathrm{ClN}_{3} \mathrm{O}_{3}$; yield: $83 \%$; white solid; mp: 80-82 ${ }^{\circ} \mathrm{C}$; ${ }^{1} \mathrm{H}-\mathrm{NMR}\left(400 \mathrm{MHz}, \mathrm{CDCl}_{3}\right) \delta 12.91$ (s, 1H), $8.06(\mathrm{~s}, 1 \mathrm{H}), 7.76(\mathrm{~d}, J=8.99 \mathrm{~Hz}, 1 \mathrm{H}), 7.67-7.58$ (m, 2H), 7.52-7.46 (m, 2H), $7.21(\mathrm{~d}, J=7.77 \mathrm{~Hz}, 2 \mathrm{H}), 7.10$ (d, $J=7.74 \mathrm{~Hz}, 2 \mathrm{H}), 6.56(\mathrm{~d}, J=1.86 \mathrm{~Hz}, 1 \mathrm{H}), 6.53-6.46$ $(\mathrm{m}, 1 \mathrm{H}), 5.32(\mathrm{~s}, 2 \mathrm{H}), 4.64(\mathrm{q}, J=6.73 \mathrm{~Hz}, 1 \mathrm{H}), 2.44(\mathrm{~d}$, $J=7.04 \mathrm{~Hz}, 2 \mathrm{H}), 1.88-1.81(\mathrm{~m}, 1 \mathrm{H}), 1.55(\mathrm{~d}, J=6.72 \mathrm{~Hz}$, $3 \mathrm{H}), 0.90(\mathrm{~d}, J=6.46 \mathrm{~Hz}, 6 \mathrm{H}) ;{ }^{13} \mathrm{C}-\mathrm{NMR}(101 \mathrm{MHz}$, $\left.\mathrm{CDCl}_{3}\right) \delta 205.2,166.4,164.7,143.6,141.2,139.3,135.5$, $133.0,131.7,131.6,130.5$ (2C), 129.4, 128.8, 128.6, 128.1(2C), 125.9, 114.3, 108.6, 103.3, 63.4, 48.2, 46.6, 31.8, 24.2 (2C), 21.0; LRMS: (ES+) $m / z=490[\mathrm{M}+1]$, $512[\mathrm{M}+\mathrm{Na}]$; HPLC $99.35 \%$, column: phenomenex luna C8 (2) (250X4.6 mm), mobile phase: $90 \%$ acetonitrile in $0.1 \%$ formic acid, flow rate: $1.0 \mathrm{~mL} / \mathrm{min}$.

\section{Biological evaluation Animals}

Wistar strain albino rats of male sex weighing 150-250 g were purchased from National Institute of Nutrition, Hyderabad, India and housed under standard environmental conditions (temperature: $24 \pm 1{ }^{\circ} \mathrm{C}$, light/dark cycle: $10 / 14 \mathrm{~h}$ ). The rats were fed with standard pellet diet (Amrut laboratory animal feed, Maharashtra, India) and water ad libitum. Animals were acclimatized to laboratory conditions at least 1 week before conducting the experiments according to the guide lines of CPCSEANew Delhi (Registration No.-915/ac/05/CPCSEA).

\section{In vivo anti-inflammatory activity}

The synthesized compounds assessed for their antiinflammatory activity using carrageenan-induced rat paw edema method. Male Wistar rats (150-250 g) were fasted with access of water at least $24 \mathrm{~h}$ prior to the experiments and were divided randomly into different groups (control, standard and the test groups) of five rats each. The rat paw edema was induced by subcutaneous injection of $0.1 \mathrm{~mL}$ of $1 \%$ freshly prepared saline solution of carrageenan into the right hind paw of rats. The standard drug ibuprofen $(10 \mathrm{mg} / \mathrm{kg}$ body weight) given orally as a positive control. The control group was administered orally with $0.9 \%$ of $0.1 \mathrm{~mL}$ of saline solution only. The test groups were administered orally with the synthesized compounds at the equimolar dosage of the standard drug, $1 \mathrm{~h}$ before the administration of carrageenan. The paw volumes were measured using plethysmometer at interval of $1 \mathrm{~h}$.

\section{Bactericidal assay \\ Bacterial strains}

Gram positive strains methicillin-resistant S. aureus (MRSA, NCTC 13616), Bacillus subtilis (ATCC 6633), Bacillus cereus (ATCC 14579) and gram negative strains Klebsiella pneumoniae (ATCC 43816), Escherichia coli (ATCC 8739), Proteus vulgaris (ATCC 13315) were procured from American type culture collection, USA. Methicillin-resistant $S$. aureus was purchased from culture collections, UK. All bacterial strains stored at $-80^{\circ} \mathrm{C}$ were streaked on Luria-Bertani (LB) agar plates (Himedia Laboratories, Mumbai, India) and incubated at $37^{\circ} \mathrm{C}$ for 20 to $24 \mathrm{~h}$. A few isolated colonies were selected from each plate and suspended in $5 \mathrm{~mL}$ of LB broth in sterile culture vessel. The vessel was plugged with cotton and incubated with gentle shaking $(140 \mathrm{rpm})$ at $37^{\circ} \mathrm{C}$ for $20 \mathrm{~h}$.

\section{Determination of bactericidal activity}

The assay was conducted to assess the bactericidal activities of synthesized compounds through microtiter plates (Lambert et al. 2001). The assay reaction mixture consisted of phosphate-buffered saline (PBS) $50 \mathrm{mM}$ sodium phosphate, $150 \mathrm{mM} \mathrm{NaCl}$ ( $\mathrm{pH} 7.0)$ ], the test compound at various concentrations and the bacterial strains were prepared in sterile 96-well microtiter plates (Nunc, Inc). The wells are filled with $100 \mu \mathrm{L}$ diluted test compounds in PBS and $50 \mu \mathrm{L}$ of the diluted bacterial strains. The wells were incubated with gentle shaking $(140 \mathrm{rpm})$ at $37^{\circ} \mathrm{C}$ for various incubation periods 0 (baseline), 2, 4, 8 , 12 and $24 \mathrm{~h}$ (time-kill studies). For positive and negative controls, a separate microtiter plate was prepared and screened for each incubation time studied $(0,2,4,8,12$ and $24 \mathrm{~h}$ ). Following incubation, a $20-\mu \mathrm{L}$ aliquot from each well was spotted at the top of a square plate containing nutrient agar medium. The plate was labelled and tapped gently to facilitate the movement of the liquid. There were approximately 200 cells in the spotted $(20-\mu \mathrm{L})$ sample. Plates were placed uncovered in biohood until the sample liquid dried (ca. $10 \mathrm{~min}$ ) and incubated overnight at $37{ }^{\circ} \mathrm{C}$. The colony forming units (CFU) for each streak were enumerated after $24 \mathrm{~h}$ using a colony counter. The number of CFU at each dilution of test compounds was compared with the average of positive control value to determine the percentage of bacteria killed per well. The percentage of the bacteria killed was plotted graphically, and the percentage of the test compound resulting decrease in the number of CFU (MIC/MBC) was determined.

\section{Molecular modelling approach}

In the present study, Hyperchem 8.0, Swiss Protein Data Base Viewer (SPDBV) 3.7 (Johansson et al. 2012) version, 
GOLD Version 2.0, ArgusLabs 4.0.1 and Discovery studio visualiser 4.1 docking programs were evaluated to determine the interactions, affinities, binding energies and selectivity's of compounds $(\mathbf{1 3 a}-\mathbf{q})$. Ligands energy minimization was carried out by using Hyperchem. 8.0 version. The protein-ligand interactions between COX-2 (PDB code 4PH9) and target molecules (13a-q) were prepared for docking studies by adding hydrogen atoms, removing water molecules, co-crystallized inhibitors and refined by using the Deep View/SPDBV. Basic amines were protonated and acidic carboxyl groups were de-protonated prior to charge calculation. Then successful docking has been performed using GOLD 2.0. GOLD was used to evaluate Chem score and Gold fitness functions. ArgusLab 4.0.1 docking software used here to visualize the binding conformations and to calculate the binding energies of the analogues $(\mathbf{1 3 a}-\mathbf{q})$. Discovery studio visualizer has been utilized to visualize the best binding poses of the final target analogues $(\mathbf{1 3 a}-\mathbf{q})$ within the active site of $4 \mathrm{PH} 9$ protein.

\section{Conclusions}

We have designed and synthesized a number of hybrid molecules containing ibuprofen-resorcinol-triazole moieties in single molecule using Click chemistry. These synthesized analogues $(\mathbf{1 3 a} \mathbf{a}-\mathbf{q})$ were screened for in vivo anti-inflammatory. Compounds 13l, 13g, 13c, 13k, 13i, 13n, 13m and 13j were shown significant activity. Most of the biological experimental values correlated with docking results. These molecular binding interactions of an in silico data demonstrated that 130 has more specificity towards the COX-2 binding site and could be a potent anti-inflammatory compound. These final derivatives were also evaluated for bactericidal activity. Compounds 13c, 13i, 131 and 130 exhibited good bactericidal profile. Finally, among all compounds 13o, 13c, 13i and 131 showed an interesting dual anti-inflammatory and antibacterial activity. These results gave us positive encouragement to develop further novel chemical entities towards challenging biological agents.

\section{Additional file}

Additional file 1. Supplementary material (Copies of ${ }^{1} \mathrm{H}-\mathrm{NMR},{ }^{13} \mathrm{C}-\mathrm{NMR}$, LRMS and HPLC) for synthesized compounds.

\section{Authors' contributions}

KKA carried out the synthesis, purification of the compounds, analyzed the data and shared in writing the manuscript. SV have been involved in the purification and drafting the manuscript. RM performed the docking studies. MR carried out the characterization of the compounds. MKT carried out the biological assay. PJP designed the research, helped in the results and discussion, shared in writing the manuscript and revised the manuscript. All authors read and approved the final manuscript.

\section{Author details}

'Department of Chemistry, University College of Science, Saifabad, Osmania University, Hyderabad, Telangana 500004, India. ${ }^{2}$ Chaitanya College of Pharmacy Education and Research, Kishanpura, Hanamkonda, Warangal, Telangana 506001, India.

\section{Acknowledgements}

KKA thanks to CSIR, New Delhi, India, for financial support in the form of senior research fellowship (SRF) and central facilities for research and development (CFRD), Osmania University, Hyderabad, India, for providing analytical support.

\section{Competing interests}

The authors declare that they have no competing interests.

Received: 22 December 2015 Accepted: 24 March 2016 Published online: 11 April 2016

\section{References}

Allison MC, Howatson AG, Torrance CJ, Lee FD, Russell RI (1992) Gastrointestinal damage associated with the use of nonsteroidal antiinflammatory drugs. N Engl J Med 327:749-754

Alsarra IA, Ahmed MO, Alanazi FK, ElTahir KEH, Alsheikh AM, Neau SH (2010) Influence of cyclodextrin complexation with NSAIDs on NSAID/cold stress-induced gastric ulceration in rats. Int J Med Sci 7:232

Bansal Y, Kaur M, Silakari O (2015) Benzimidazole-ibuprofen/mesalamine conjugates: potential candidates for multifactorial diseases. Eur J Med Chem 89:671-682

Dunn G, Hoover J, Berges D, Taggart J, Davis L, Dietz E, Jakas D, Yim N, Actor P, Uri J (1976) Orally active 7-phenylglycyl cephalosporins. Structure-activity studies related to cefatrizine (SK\&F 60771). J Antibiot 29:65-80

Guo L, Ye C, Chen W, Ye H, Zheng R, Li J, Yang H, Yu X, Zhang D (2008) Antiinflammatory and analgesic potency of carboxyamidotriazole, a tumorostatic agent. J Pharmacol Exp Ther 325:10-16

Haftchenary S, Jouk AO, Aubry I, Lewis AM, Landry M, Ball DP, Shouksmith AE, Collins CV, Tremblay ML, Gunning PT (2015) Identification of bidentate salicylic acid inhibitors of PTP1B. ACS Med Chem Lett 6:982-986

Johansson MU, Zoete V, Michielin O, Guex N (2012) Defining and searching for structural motifs using DeepView/Swiss-PdbViewer. BMC Bioinformatics 13:173

Kalgutkar AS, Crews BC, Rowlinson SW, Marnett AB, Kozak KR, Remmel RP, Marnett $L J$ (2000a) Biochemically based design of cyclooxygenase-2 (COX-2) inhibitors: facile conversion of nonsteroidal antiinflammatory drugs to potent and highly selective COX-2 inhibitors. Proc Natl Acad Sci USA 97:925-930

Kalgutkar AS, Marnett AB, Crews BC, Remmel RP, Marnett LJ (2000b) Ester and amide derivatives of the nonsteroidal antiinflammatory drug, indomethacin, as selective cyclooxygenase-2 inhibitors. J Med Chem 43:2860-2870

Kalgutkar AS, Rowlinson SW, Crews BC, Marnett LJ (2002) Amide derivatives of meclofenamic acid as selective cyclooxygenase-2 inhibitors. Bioorg Med Chem Lett 12:521-524

Kumar D, Khare G, Kidwai S, Tyagi AK, Singh R, Rawat DS (2014) Synthesis of novel 1,2,3-triazole derivatives of isoniazid and their in vitro and in vivo antimycobacterial activity evaluation. Eur J Med Chem 81:301-313

Lambert R, Skandamis PN, Coote PJ, Nychas GJ (2001) A study of the minimum inhibitory concentration and mode of action of oregano essential oil, thymol and carvacrol. J Appl Microbiol 91:453-462

Lazzaroni M, Bianchi Porro G (2004) Gastrointestinal side-effects of traditional non-steroidal anti-inflammatory drugs and new formulations. Aliment Pharmacol Ther 20:48-58

Lee JH, Gupta S, Jeong W, Rhee YH, Park J (2012) Characterization and utility of $\mathrm{N}$-unsubstituted imines synthesized from alkyl azides by ruthenium catalysis. Angew Chem Int Ed 51:10851-10855

Liang SH, Southon AG, Fraser BH, Krause-Heuer AM, Zhang B, Shoup TM, Lewis R, Volitakis I, Han Y, Greguric I, Bush Al, Vasdev N (2015) Novel fluorinated 8-hydroxyquinoline based metal ionophores for exploring the metal hypothesis of Alzheimer's disease. ACS Med Chem Lett 6:1025-1029 
Liu Y, Yan W, Chen Y, Petersen JL, Shi X (2008) Efficient synthesis of $\mathrm{N}$-2-aryl-1,2,3-triazole fluorophores via post-triazole arylation. Org Lett 10:5389-5392

Mishra A, Veerasamy R, Jain PK, Dixit VK, Agrawal RK (2008) Synthesis, characterization and pharmacological evaluation of amide prodrugs of ketorolac. Eur J Med Chem 43:2464-2472

Orlando BJ, Lucido MJ, Malkowski MG (2015) The structure of ibuprofen bound to cyclooxygenase-2. J Struct Biol 189:62-66

Rao PS, Kurumurthy C, Veeraswamy B, Kumar GS, Poornachandra Y, Kumar CG, Vasamsetti SB, Kotamraju S, Narsaiah B (2014) Synthesis of novel 1,2,3-triazole substituted- $N$-alkyl/aryl nitrone derivatives, their anti-inflammatory and anticancer activity. Eur J Med Chem 80:184-191

Romeo E, Ponzano S, Armirotti A, Summa M, Bertozzi F, Garau G, Bandiera T, Piomelli D (2015) Activity-based probe for $N$-acylethanolamine acid amidase. ACS Chem Biol 10:2057-2064

Rostovtsev V, Green LG, Fokin VV, Sharpless KB (2002) A stepwise huisgen cycloaddition process: copper(I)-catalyzed regioselective "ligation" of azides and terminal alkynes. Angew Chem Int Ed 41:2596-2599

Ruiz J, Lowenthal D (1997) NSAIDS and nephrotoxicity in the elderly. Geriatr Nephrol Urol 7:51-57

Shafi S, Alam MM, Mulakayala N, Mulakayala C, Vanaja G, Kalle AM, Pallu R, Alam M (2012) Synthesis of novel 2-mercapto benzothiazole and 1,2,3-triazole based bis-heterocycles: their anti-inflammatory and antinociceptive activities. Eur J Med Chem 49:324-333

Shanbhag VR, Crider AM, Gokhale R, Harpalani A, Dick RM (1992) Ester and amide prodrugs of ibuprofen and naproxen: synthesis, anti-inflammatory activity, and gastrointestinal toxicity. J Pharm Sci 81:149-154

Tan H, Ong W, Lai S, Chow W (2007) Nimesulide-induced hepatotoxicity and fatal hepatic failure. Singapore Med J 48:582-585
Thompson M (2004) Molecular docking using ArgusLab, an efficient shapebased search algorithm and the AScore scoring function. In ACS meeting, Philadelphia, p 42

Tornøe CW, Christensen C, Meldal M (2002) Peptidotriazoles on solid phase: [1,2,3]-triazoles by regiospecific copper(I)-catalyzed 1,3-dipolar cycloadditions of terminal alkynes to azides. J Org Chem 67:3057-3064

Tozkoparan B, Gökhan N, Aktay G, Yeşilada E, Ertan M (2000) 6-Benzylidenethiazolo [3,2-b]-1,2,4-triazole-5 (6 h)-onessubstituted with ibuprofen: synthesis, characterizationand evaluation of anti-inflammatory activity. Eur J Med Chem 35:743-750

Verdonk ML, Cole JC, Hartshorn MJ, Murray CW, Taylor RD (2003) Improved protein-ligand docking using GOLD. Proteins Struct Funct Bioinform 52:609-623

Wacharasindhu S, Bardhan S, Wan Z-K, Tabei K, Mansour TS (2009) Oxidative palladium catalysis in SNAr reactions leading to heteroaryl ethers from pyridotriazol-1-yloxy heterocycles with aryl boronic acids. J Am Chem Soc 131:4174-4175

Winter CA, Risley EA, Nuss GW (1962) Carrageenin-induced edema in hind paw of the rat as an assay for antiinflammatory drugs. Exp Biol Med 111:544-547

Yadav MR, Nimekar DM, Ananthakrishnan A, Brahmkshatriya PS, Shirude ST, Giridhar R, Parmar A, Balaraman R (2006) Synthesis of new chemical entities from paracetamol and NSAIDs with improved pharmacodynamic profile. Bioorg Med Chem 14:8701-8706

Yang Y, Rasmussen BA, Shlaes DM (1999) Class A $\beta$-lactamases-enzymeinhibitor interactions and resistance. Pharmacol Ther 83:141-151

\section{Submit your manuscript to a SpringerOpen ${ }^{\circ}$ journal and benefit from:}

- Convenient online submission

- Rigorous peer review

- Immediate publication on acceptance

- Open access: articles freely available online

- High visibility within the field

- Retaining the copyright to your article

Submit your next manuscript at $>$ springeropen.com 